\title{
STATISTICAL GEOCHEMISTRY REVEALS DISRUPTION IN SECULAR LITHOSPHERIC EVOLUTION ABOUT 2.5 GYR AGO
}

\author{
PREPRINT \\ C. Brenhin Keller $^{1^{*}}$ and Blair Schoene ${ }^{1}$ \\ ${ }^{1}$ Department of Geosciences, Guyot Hall, Princeton University, Princeton, NJ 08544
}

\begin{abstract}
Secular cooling of the Earth is required by surface heat loss and declining radiogenic heat production over the last 4.5 billion years. Igneous geochemistry has been used to understand how changing heat flux influenced Archean geodynamics [1], but records of systematic geochemical evolution are complicated by heterogeneity of the rock record and uncertainties regarding selection and preservation bias [2, 3, 4]. We apply statistical sampling techniques to a geochemical database of $\sim 70,000$ samples from the continental igneous rock record to produce the first comprehensive record of secular geochemical evolution throughout Earth history. Consistent with secular mantle cooling, compatible and incompatible elements in basalts record gradually decreasing mantle melt fraction through time. Superimposed on this gradual evolution is a pervasive geochemical discontinuity ca. $2.5 \mathrm{Ga}$, including dramatic decreases in mantle melt fraction in basalts, and in deep crustal melting/fractionation indicators such as $\mathrm{Na} / \mathrm{K}, \mathrm{Eu} / \mathbf{E u}$, and $\mathrm{La} / \mathrm{Yb}$ of felsic rocks. Along with increased preserved crustal thickness across the Archean-Proterozoic boundary [5, 6], these data are consistent with a model where high degree Archean mantle melting produced a thick, mafic lower crust and consequent deep crustal delamination and anatexis in turn resulting in abundant tonalite-tronhjemite-granodiorite (TTG) magmatism and a thin preserved Archean crust. Coincidence of the observed changes in geochemistry and crustal thickness with stepwise atmospheric oxidation [7] at the end of the Archean provides the most significant temporal link between deep earth geochemical processes and the rise of atmospheric oxygen on Earth.
\end{abstract}

While it is generally expected that mantle potential temperatures were higher in the Archean, the ratio of terrestrial heat production to heat loss through time is very poorly constrained [8]. The resulting lack of confidence in models of secular thermal evolution has contributed to uncertainty regarding the style of Archean geodynamics, given the temperature dependance of rock deformation mechanisms, mantle and crustal melting, and magma geochemistry [1]. The existence of high percent melt rocks such as komatiites, the predominance of the high-Na TTG series, and the purported structural evolution of granite-greenstone terranes have all been used to suggest that plate tectonics may have been different in style or even nonexistent during the Archean [9]. However, thermobarometric estimates of crustal geotherms similar to those of modern continents, geochronological evidence for tectonic-scale underthrusting, and the reported occurrence of subduction signatures such as high-field-strength element depletion have led other authors to argue that plate tectonics has existed in its present state since at least 3.0 or as early as $3.8 \mathrm{Ga}[9,10]$.

Much like those generated in modern tectonic environments, rocks from preserved Archean crust are characterized by extreme geochemical heterogeneity. To obtain systematic trends from this record, studies of igneous geochemistry over Earth history have typically relied on small, carefully selected datasets from well characterized terranes [11, 3, 12]. The present study takes a different approach on the basis that a sufficiently large, representative dataset can be used to define global geochemical averages very precisely; changes in this average over time should reflect the influence of long-term geodynamic drivers such as mantle temperature.
To this end, we have constructed a database of $\sim 70,000$ major and trace element whole-rock analyses from preexisting sources [11, 3, 4, 13] that report sample location as well as crystallization age and uncertainty. These data are superimposed on existing geophysical models Crust 2.0 [14] and TC1 [5] that estimate present-day crustal and lithospheric parameters. Results for global mean geochemistry with time are generated by Monte Carlo analysis with weighted bootstrap resampling (Methods). Resampling weights are inversely related to spatiotemporal sample density in order to achieve a maximally uniform posterior sample density distribution and minimize selection bias. The result is a best estimate of the average igneous geochemistry of exposed continental crust through time, reported as means with associated 2- $\sigma$ standard errors of the mean for $100 \mathrm{Ma}$ intervals between 0 and $3.8 \mathrm{Ga}$. In order to distinguish between primary mantle melting and subsequent evolution and fractionation processes, we extract results from two silica ranges: $62-74 \% \mathrm{SiO}_{2}$ for intermediate to felsic samples and $43-51 \% \mathrm{SiO}_{2}$ for less fractionated mafic samples.

The results for the least fractionated $\left(43-51 \% \mathrm{SiO}_{2}\right)$ mafic samples preserved in the continental igneous rock record reveal a systematic decrease in compatible element concentration along with a corresponding increase in incompatible element concentration through time (Figure 1). These trends can be shown to reflect decreases in mantle partial melting through time, as a consequence of secular mantle cooling; alternative explanations such as a change in the degree of fractionation through time are found to be incompatible with the observed data (Methods; Supplementary Figures 8-9). While such low silica samples do not generally represent primitive melts, compositional trends in 


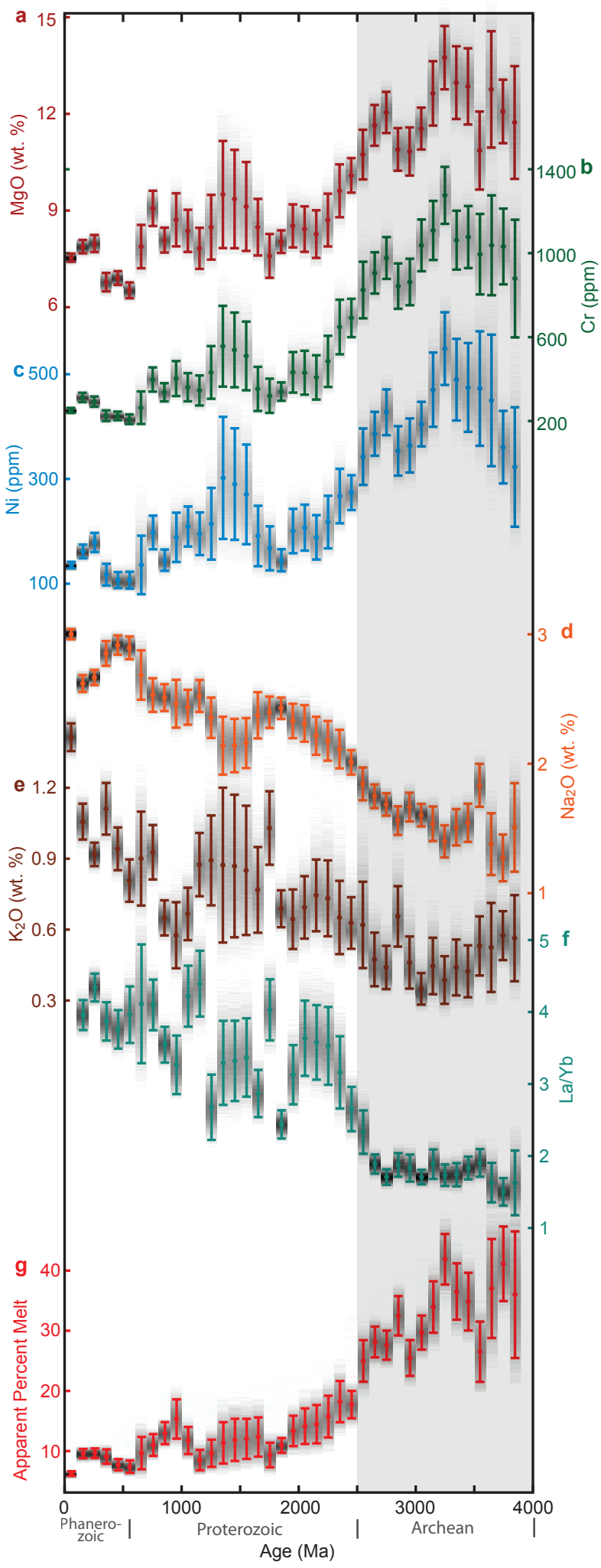

Figure 1: Secular compositional evolution of mafic lithologies. Secular mantle cooling is illustrated by compatible (a-c) and incompatible (d-e) element trends over time in relatively unfractionated rocks (43$51 \% \mathrm{SiO}_{2}$ ), along with corresponding $\mathrm{La} / \mathrm{Yb}(\mathbf{f})$ and percent melt (g) Error bars show 2- $\sigma$ standard errors of the mean; shading illustrates density of the individual Monte Carlo simulations. these samples nonetheless reflect source processes given a representative dataset, allowing for the estimation of minimum percent mantle partial melting through time (Methods). In order to derive such minimum estimates, we applied least-squares optimization to match thermodynamic batch melting simulations of primitive mantle from MELTS [15, 16] with Monte Carlo simulations of basaltic major element concentrations through time (Methods). The results (Figure 1g) show a systematic decrease in mantle melt fraction from $\sim 0.35$ in the Archean to $\sim 0.1$ at the present. These results agree well with studies of mantle xenoliths which estimate that Archean subcontinental mantle lithosphere was produced through $\sim 40 \%$ melt extraction [17].

In addition to the gradual trend expected from secular cooling, however, our results indicate a sudden, systematic $\sim 10$ percentage point decrease in average percent mantle melting at $\sim 2.5$ Ga (Figure 1g). Due to Earths thermal inertia, it is unlikely that this event is the result of a rapid change in mantle potential temperature. While a rapid change in the style of tectonics and crust formation at $\sim 2.5 \mathrm{Ga}$ could provide one possible explanation for the rapid decrease in average mantle melting, an abrupt response in degree of melting to a gradual cooling path may provide a more parsimonious explanation; both experiments and thermodynamic models indicate substantially nonlinear mantle melting as a function of temperature, with notable inflections corresponding to clinopyroxene exhaustion [18]. Trace element geochemistry provides some additional insight: simple trace element modelling (Methods) suggests that the drastic increases in $\mathrm{La} / \mathrm{Yb}$ (Figure 1f), $\mathrm{La} / \mathrm{Sm}$, and $\mathrm{Sm} / \mathrm{Yb}$ cannot be explained by the trend in degree of mantle melting in Figure if alone, indicating a change in either trace element composition of the source or effective bulk partition coefficients.

Geochemical trends in high silica $\left(62-74 \% \mathrm{SiO}_{2}\right)$ rocks parallel many of those observed in basalts. Sodium, however, represents a notable exception. The high $\mathrm{Na} / \mathrm{K}$ (Figure 2b) and $\mathrm{Na} /(\mathrm{Ca}+\mathrm{Na}+\mathrm{K})$, of the TTG series have pervaded the discussion of Archean crust formation [11, 3, 19, 4, 20, 21]. These geochemical signatures, along with high LREE/HREE ratios (e.g., $\mathrm{La} / \mathrm{Yb}$; Figure 2a), have been used to argue for the formation of TTG by high pressure $(>40 \mathrm{~km})$ partial melting of metabasalt at pressures above the Na-plagioclase stability field in the presence of restitic amphibole and/or garnet $[11,3,19,4,20,21]$. Experimental data for partial melting of mafic rocks at mid to lower crustal pressures and temperatures have demonstrated a positive correlation between pressure and sodium concentration in the melt [20]. Trace element results from our dataset show correlations predicted by such a model: the secular evolution of $\mathrm{Eu} / \mathrm{Eu}^{*}$ and $\mathrm{Sr}$ (Figure $2 \mathrm{c}, \mathrm{d}$ ) parallels that of $\mathrm{Na} / \mathrm{K}$ in felsic rocks, arguing that deep crustal melting (and/or high pressure fractional crystallization [22]) played a larger role in forming preserved Archean crust than post-Archean crust.

The two most frequently proposed settings for such deep crustal anatexis and TTG generation are 1) melting of subducted oceanic crust, and 2) melting of overthickened mafic lower crust, which derives its basalt from mantle melting and crustal underplating $[19,21]$. Of these, the latter provides a potential genetic link between TTG generation and observed high percent mantle melting in the Archean: extensive basalt production could lead to a thicker and/or more mafic lower continental 


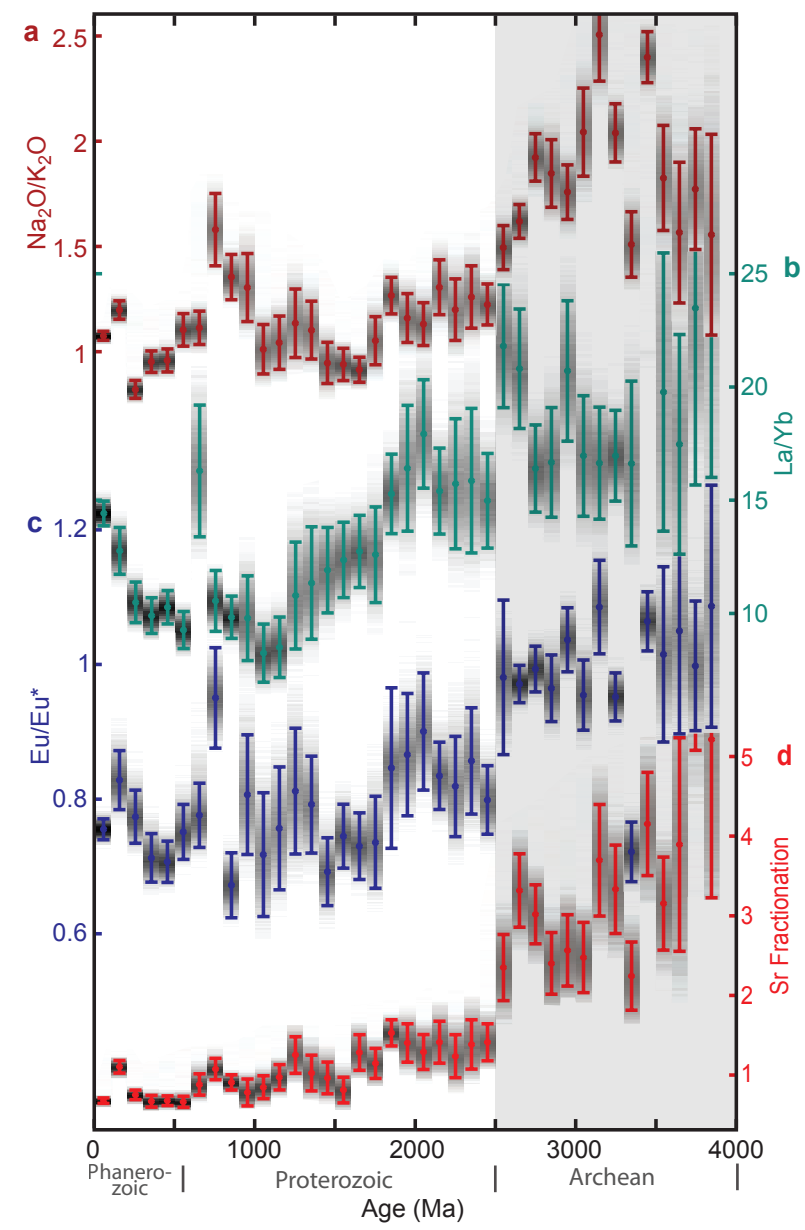

Figure 2: Secular compositional evolution of felsic lithologies. A shift in lithospheric evolution is suggested by trace element patterns in felsic rocks $\left(62-73 \% \mathrm{SiO}_{2}\right)$ (a-c) along with the relative abundance of $\mathrm{Sr}$ in rocks with $62-73 \% \mathrm{SiO}_{2}$ normalized to $\mathrm{Sr}$ in $43-51 \% \mathrm{SiO}_{2}$ samples (d). As $\mathrm{Na}, \mathrm{Eu}$, and $\mathrm{Sr}$ are all partitioned into into plagioclase, higher abundance of these elements corresponds to decreased plagioclase fractionation. Error bars show 2- $\sigma$ standard errors of the mean; shading illustrates density of the individual Monte Carlo simulations.

crust that would more often result in TTG generation. However, any process requiring a thick Archean crust creates an apparent dilemma: preserved Archean lithosphere is characterized by unusually thin crust [6] (Figure 3a). Crustal delamination provides one potential solution, in which crustal thickening leads to a lower crust of dense garnet pyroxenite that can break off and founder into the mantle triggering an influx of hot asthenosphere that leads to lower crustal anatexis, crustal uplift, and magmatism [23]. Overthickening of mafic lower crust therefore leads to delamination, crustal thinning, and further deep crustal magmatism. Indeed, previous workers have suggested that lower crustal delamination was more prevalent in the Archean, a process that would have been facilitated by high Archean mantle potential temperatures [21, 24]. Further, since delamination involves a pressure and temperature dependent critical crustal thickness [24], delamination may relate gradual secular cooling to rapid change in the geochemical record. Archean delamination thus provides a link between high degree man- tle melting, TTG abundance, dramatic geochemical shifts near the Archean/Proterozoic boundary, and thin preserved Archean crust.

While uncertainty in the timing of the observed geochemical transition is estimated to be on the order of ś $100 \mathrm{Ma}$, our results nonetheless reveal a striking temporal coincidence between a major discontinuity in the character of preserved continental lithosphere and the atmospheric great oxidation event (GOE) near the Archean/Proterozoic boundary (Figures 1-3). It is generally agreed that the atmosphere was mostly anoxic prior to $\sim 2.4 \mathrm{Ga}$ based on measurements of mass-independent sulfur isotope fractionation in pyritic shales [25], occurrence of banded iron formations [26], and the presence of reduced detrital grains (sulfides) in Archean sediment [28] (Figure 3e). However, the cause of subsequent atmospheric oxidation remains a matter of debate; some indications suggest the GOE did not occur for at least several hundred million years after the evolution of photosynthesis, leading some to argue that an additional geological stimulus was required to trigger widespread atmospheric oxidation [29, 30].

Proposed mechanisms that could link the deep Earth to atmospheric oxidation at the end of the Archean include a change in mantle oxygen fugacity [29], or a change in magma degassing style (subaerial vs. subaqueous) [30], where both influence the atmosphere via the flux of reduced volcanic volatiles. However, studies of mantle redox proxies such as $\mathrm{V} / \mathrm{Sc}$, including our own analysis (Supplementary Figure 11), indicate that upper mantle oxygen fugacity has remained roughly constant over the last $3.8 \mathrm{Ga}$ [12]. The latter process remains plausible, but it is not immediately clear how this mechanism would link to our observed geochemical trends.

However, despite providing useful constraints on mantle oxygen fugacity, redox tracers such as $\mathrm{V} / \mathrm{Sc}$ best record changes in oxygen fugacity of the mantleprimitive melt system, not subsequent magma fractionation and evolution; consequently, constraints on the redox state of magmas during evolution and fractionation in the crust are largely absent [31]. Magmatic redox fractionation is controlled by $D_{\text {mineral }}^{F e^{3+}} / D_{\text {mineral } / \text { melt }}^{F e^{2+}}$ distribution coefficients, which are very poorly characterized. However, as shown by experimental iron speciation studies, eclogitic minerals such as garnet and sodic clinopyroxene are capable of accommodating substantial $\mathrm{Fe}^{3+}$, and have moderately elevated $\mathrm{Fe}^{3+} / \mathrm{Fe}^{2+}$ ratios compared other common restitic minerals such as olivine [32,33]. Consequently, melt extraction from an eclogitic or garnet pyroxenitic restite, as is expected during TTG genesis, could lead to lower melt $\mathrm{Fe}^{3+} / \mathrm{Fe}^{2+}$ relative to melt extracted from a low pressure restite rich in olivine (which contains substantial $\mathrm{Fe}$ but very low $\left.\mathrm{Fe}^{3+} / \mathrm{Fe}^{2+}\right)[32,33]$ and plagioclase (which contains high $\mathrm{Fe}^{3+} / \mathrm{Fe}^{2+}$ but very little total $\mathrm{Fe}$ ) [33]. TTG magmatism may therefore leave more oxidizing power in eclogitic residue in the form of $\mathrm{Fe}^{3+}$, while more reducing power is transported to the surface in the form of $\mathrm{Fe}^{2+}$ and equilibrated volatile species such as $\mathrm{H}_{2} \mathrm{~S}, \mathrm{CH}_{4}$, and $\mathrm{CO}$.

In this context, Archean deep crustal magmatism provides a potentially significant influence on surficial oxygen fugacity: simple stoichiometric calculations show that a $15 \%$ change in restitic $\mathrm{Fe}^{3+} / \Sigma \mathrm{Fe}$ for a modest $5 \mathrm{~km}^{3} / \mathrm{yr}$ magmatic flux would result in an increase in magma reducing capacity by approximately $4.0 * 10^{12} \mathrm{~mol} e^{-} / \mathrm{yr}$, similar in magnitude to the en- 


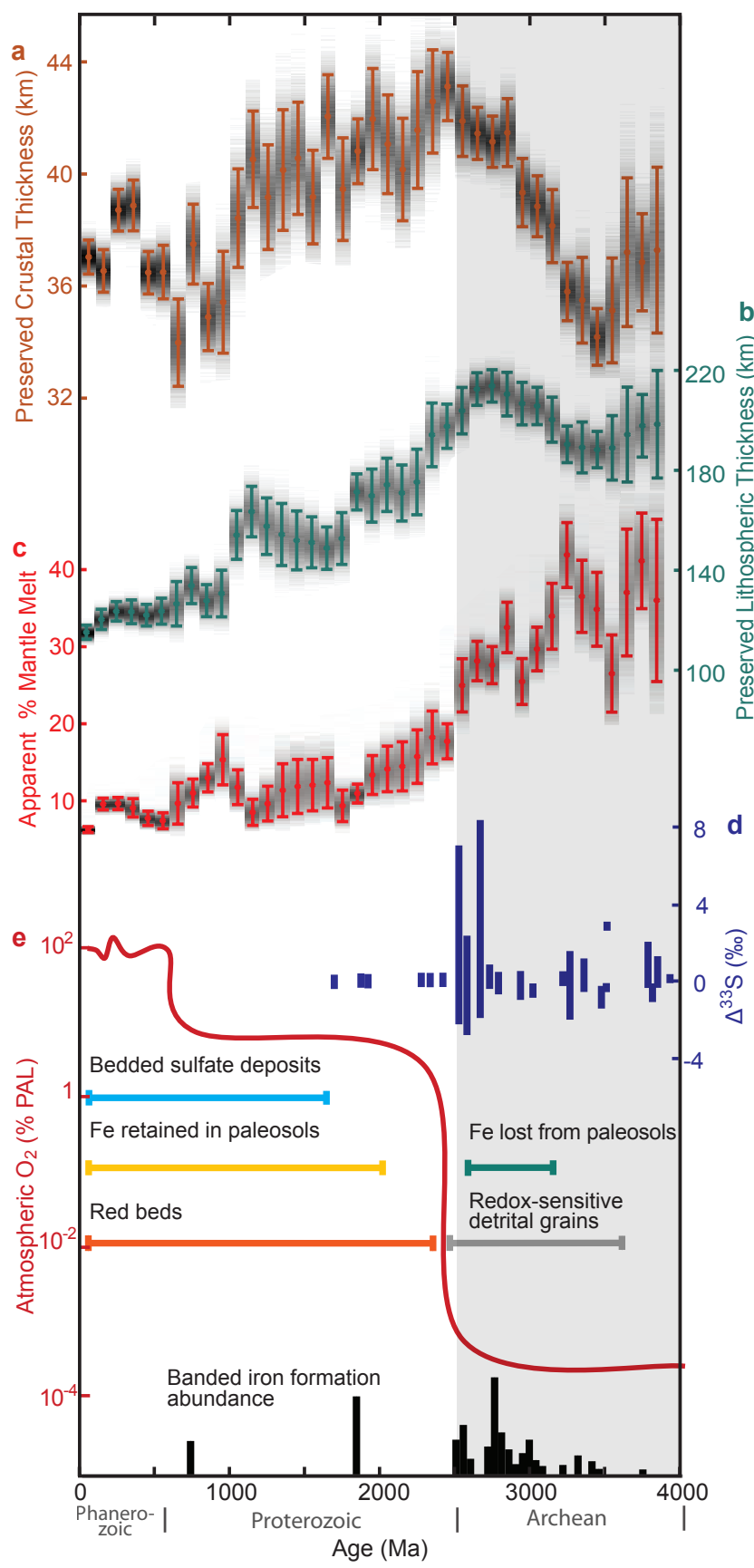

Figure 3: Relationship of lithospheric evolution and atmospheric oxidation. A notable temporal coincidence is observed between shifts in (a-b) preserved crustal and lithospheric thickness (this study, based on the models of Bassin et al. [14] and Artemieva [5]), (c) average percent mantle melting (this study), and (d-e) atmospheric oxidation as shown by generalized atmospheric oxygen curve (adapted from Kump [7]), ${ }^{33} \mathrm{~S}$ fractionation [25], and the presence of sedimentary of redox indicators [26, 27, 28]. tire present day volcanic volatile reducing flux (Methods). Although it is not simple to determine if the termination of this additional reducing flux at the end of the Archean would be sufficient to trigger atmospheric oxidation, the magnitude of the flux may be constrained by further study of restitic iron partitioning.

Though speculative, restitic redox partitioning provides a testable mechanism to explain the correlation of atmospheric oxidation with the $\sim 2.5 \mathrm{Ga}$ geochemical transition revealed by our analysis. It is not yet clear whether these changes represent a fundamental shift in the style of crust formation and tectonics or simply an abrupt response of melt production to gradual secular cooling. However, delamination and subsequent lower crustal anatexis provide potential explanations for the observed geochemical trends in felsic rocks that are largely independent of the style of Archean tectonics. Our analysis illustrates the opportunity presented by recent efforts to make large amounts of published geochemical data readily available and amenable to statistical analysis. These initial results substantiate the existence of a period of profound change in the Earth system near the Archean/Proterozoic boundary with implications for crustal differentiation, atmospheric oxidation, and the habitability of Earth for complex aerobic biota.

\section{Methods}

\subsection{Database compilation}

A database of major and trace element analyses of $\sim 70,000$ igneous whole-rock samples was assembled from a number of preexisting sources, including 2500 from Condie [11], Condie and O'Neill [3], $\sim 1500$ from Moyen [4], Moyen and Stevens [20], and the remaining majority from the EarthChem repository (encompassing samples from Navdat, Georoc, and the USGS) [13]. Each sample was paired with a geospatial location, with preexisting location data supplemented by new estimates when necessary. Geochemical data for individual samples was then coupled with crustal and lithospheric thickness, crustal $\mathrm{Vp}$, Vs, and density by superimposing sample locations onto high spatial-resolution global crustal and lithospheric models CRUST 2.0 [14] and TC1 [5], respectively. To minimize the chance of introducing any unintentional selection bias, outliers were not removed from the database except in cases where the recorded data was demonstrably unphysical. The result was a dataset including up to 98 defined variables (e.g., sample age, $\mathrm{SiO}_{2}, \mathrm{La}$, crustal thickness, etc.) for each of the $\sim 70,000$ samples, for a total of more than 3.9 million defined datapoints.

\subsection{Monte Carlo analysis}

Estimates of all variables of interest were generated by Monte Carlo analysis with weighted bootstrap resampling, as illustrated for one scenario in Supplementary Figure 1. Sample weights were assigned to be inversely dependent on spatiotemporal sample density according to the relationship

$$
W_{i} \propto 1 / \sum_{j=1}^{n}\left(\frac{1}{\left(\left(z_{i}-z_{j}\right) / a\right)^{2}+1}+\frac{1}{\left(\left(t_{i}-t_{j}\right) / b\right)^{2}+1}\right)
$$

where $\mathrm{n}$ is the number of samples in the database, $\mathrm{z}$ is spatial location, $\mathrm{t}$ is age of the rock, and $\mathrm{a}$ and $\mathrm{b}$ are normalization coefficients of 1.8 arc degrees $(\sim 200 \mathrm{~km})$ and $38 \mathrm{Ma}$, respectively. After calculation of weight Wi for each sample $i$ in the database, bootstrap resampling was 
carried out in the following steps: (1) A subset of data were randomly selected such that the probability of inclusion in the resampled subset is directly proportional to sample weight. (2) A synthetic dataset for each sampled datapoint was drawn from a Gaussian distribution with a mean equal to the original value of the datapoint and standard deviation equal to the estimated $1 \sigma$ uncertainty of the datapoint. (3) The resulting data was sorted into $100 \mathrm{Ma}$ bins, with a mean and variance calculated for each variable. (4) Steps 1-3 were repeated 10,000 times (5) A total mean and standard error of the mean were calculated for each variable in each bin. In order to distinguish between processes of mantle melting and subsequent evolution and fractionation, the entire procedure was conducted separately for samples from each of four silica ranges $(43-51 \%, 51-62 \%, 62-74 \%$ and $74-80 \%)$.

Due to the large quantity of random numbers required for Monte Carlo simulation, randomness in steps 1 and 2 was simulated with the Mersenne Twister pseudorandom number generator [34] as implemented by MATLAB. In order to assess the efficacy of the resampling procedure, prior and posterior density distributions were compared to the ideal case for latitude, longitude, and time, (Supplementary Figure 2). The results suggest substantial improvement in sampling quality, although tradeoffs exist between uniform sampling through time and uniform sampling in space. To evaluate the applicability of mean and standard error as appropriate statistics to characterize the results of Monte Carlo simulation, the distribution of sample means was examined and found to be approximately Gaussian as illustrated for one variable in Supplementary Figure 3. This is expected as a consequence of the Central Limit Theorem; regardless of the distribution of a dataset, the distribution of the mean of the dataset will naturally tend towards a Gaussian distribution. Finally, to mitigate the undesirable statistical properties of ratios with small denominators and minimize the effect of outliers, geochemical ratios such as $\mathrm{La} / \mathrm{Yb}$ were calculated first as fractions $($ e.g., $\mathrm{La} /(\mathrm{La}+\mathrm{Yb}))$ during Monte Carlo analysis and averaging, and subsequently converted to ratios for presentation; the resulting fractional averages are more robust than but not directly comparable to the average of a simple ratio.

In contrast to the widely-discussed episodic nature of crust formation (e.g., [35]), our analysis attempts to produce a uniform record by reducing the weight of abundantly sampled time periods or terranes. For instance, in accordance with Equation 1, rock samples from a time period poorly represented in the database will be bootstrap-resampled more heavily than those from periods where much crust is preserved. However, as Equation 1 attempts to balance optimal sampling through in space and optimal sampling through time, periods where very few data are preserved (e.g., 2.6-2.2 Ga) will remain more poorly sampled, resulting in larger standard errors of the mean at these times. Additionally, spatiotemporal sample weighting in conjunction with Monte Carlo sampling of rocks with large reported age uncertainties result in a continuous geochemical record that smooths out stochastic and stepwise transitions; the slopes of any abrupt trends presented herein are therefore minimum estimates. The nature of the Monte Carlo sampling process has the additional consequence that there is no uniform or single-valued age uncertainty for the resulting trends. However, temporal uncertainty in the results is generally on the order of 100 Ma.

\subsection{Response of the Monte Carlo technique the distribution of the uncertainty of the data}

While our Monte Carlo analysis does not assume any specific statistical distribution for the geochemical, geochronological, or geophysical data, it is necessary to specify the distribution of the uncertainties associated with each individual data point in our database. Since this uncertainty will be a product of the convolution of multiple independent error sources, it is reasonable to conclude that the distribution of the uncertainty will approach a Gaussian distribution in accordance with the Central Limit Theorem (similar rationale explain why the distribution of the mean of the data approaches a Gaussian distribution (Supplementary Figure 3) even though the distribution of the data is not Gaussian). In the sources from which we compiled the database, geochronological data is implied to be Gaussian in accordance with standard practice; no uncertainty is reported for individual geochemical data, but uncertainties for the analytical methods used are typically on the order of a few percent. Consequently we have conducted Monte Carlo analysis using the reported geochronological uncertainty for each data point, and assuming a $\pm 2 \sigma$ uncertainty of $4 \%$ with a Gaussian distribution for the geochemical data, as described in section 1.2 above. In order to ensure that the this choice of distribution does not bias the distribution of the results, two numerical experiments were carried out.

First, in order to demonstrate that the choice of error distribution used in Monte Carlo analysis does not bias the distribution of the data or its mean in the one-dimensional case, three Monte Carlo experiments were conducted using 1) a Gaussian distribution; 2) a lognormal distribution; and 3) a chi-squared distribution with 1 degree of freedom. Using two test datasets $(\mathrm{MgO}$ content of mafic igneous samples between 400 and $410 \mathrm{Ma}$, and a synthetic lognormal distribution), a 10,000-run Monte Carlo simulation was then conducted using each distribution for each data set to simulate the effect of $4 \%(2 \sigma)$ analytical error the same analytical error as is assumed for geochemical data in the Monte Carlo analysis of our 70,000-sample geochemical dataset. As seen in Supplementary Figure 4, for both the $\mathrm{MgO}$ data (a-d) and the simulated distribution (e-h), while the choice of error distribution may influence the small-scale smoothness of the resulting data distribution, there is no bias to the overall distribution (as particularly evident in e-h), and no bias to the mean of the distribution (red vertical lines).

To further demonstrate that the choice of statistical distribution to represent analytical error does not bias our Monte Carlo results, we conducted our full Monte Carlo analysis (as in section 1.2) for three different combinations of error distributions. Supplementary Figure 5 shows the results as a typical example for $\mathrm{MgO}$ in mafic samples (43-51\% $\mathrm{SiO}_{2}$ ) using (a) a Gaussian distribution for both geochemical error and geochronological error (as in Figures 1-3); (b) a Gaussian distribution for geochronological error and a log-normal distribution for geochemical error; and (c) a log-normal distribution for both geochemical error and geochronological error. As seen in Supplementary Figure 5, the resulting trend in $\mathrm{MgO}$ through time is nearly identical in each case. We conclude that the choice of error distribution in our Monte Carlo analysis has little to no effect on the resulting trends.

\subsection{Response of the Monte Carlo results to regions of missing data}

Due to the well known paucity of early Proterozoic igneous rocks [36], it may be argued that the position and/or shape of the $\sim 2.5 \mathrm{Ga}$ geochemical transition that we observe may be influenced by a lack of data in this period. In our dataset, this lack of data is particularly pronounced between 2200 and $2600 \mathrm{Ma}$, a period during which the temporal density of geochemical data is only $\sim 5$ percent of that at the pronounced data peaks at 2100 and $2700 \mathrm{Ma}$. Consequently, we have conducted additional tests to examine the sensitivity of the Monte Carlo technique to periods of sparse data. First, a 10,000-point synthetic dataset was generated using a log-normal distribution, with an abrupt shift in the mean and variance of the data at $2500 \mathrm{Ma}$. Then, varying amounts of data were deleted in the period from 2200 to 2600 $\mathrm{Ma}$, ranging from $100 \%$ of data present to $0 \%$ of data present (all deleted). The dataset was then subjected to Monte Carlo analysis as in section 1.2 above, using an average age uncertainty of $22 \mathrm{Ma}$ and $4 \%$ analytical error. As seen in Supplementary Figure 6, an abrupt transition as seen in Figure 1g and Figure 2b-d may may be preserved to some degree down to the point of 5\% data remaining, with $1 \%$ and $0 \%$ of the data preserved, only a smooth transition is observed. Similarly, 
deleting data from a continuous starting distribution will not result in any discontinuity in the resulting Monte Carlo output, only a large increase in uncertainty in the data-poor region (Supplementary Figure 7) Consequently, it appears unlikely that the observed abrupt transitions in secular geochemical evolution could be a product of the scarcity of early-Proterozoic data. More gradual transitions such as in Figure $1 \mathrm{f}$ may be influenced by a lack of data; although such trends still provide a convincing evidence for a major geochemical transition, the timing and rapidity of that transition is less certain. Although the dearth of data between $\sim 2200$ and $\sim 2600$ Ma may contribute in cases such as Figure $1 \mathrm{f}$ to the uncertainty in the timing of the observed geochemical transition, it remains the case that between the uncertainty in the timing of this transition and the uncertainty in the timing of the Great Oxidation Event, these two events easily overlap within uncertainty.

\subsection{Interpretation of major element trends}

Assuming our dataset provides a representative sample of the crust, four candidate mechanisms could explain the observed trends (Figure 1) in compatible and incompatible element composition of mafic rocks: (1) similar degree melting from a mantle that is more enriched now than in the past; (2) higher degrees of crustal contamination of otherwise identical basalts in the present; (3) higher degrees of fractionation in the present; or (4) higher mantle melt fraction in the past, due to either higher temperature or higher water content. A modern-day mantle that is more enriched now than in the Archean is inconsistent with well-established evidence from $\mathrm{Nd}, \mathrm{Sr}$, and $\mathrm{Hf}$ isotopic studies of midocean ridge basalts $[37,38]$, eliminating mechanism (1). Increasing crustal contamination (2) should be reflected in ratios such as $\mathrm{Nb} / \mathrm{U}$ and $\mathrm{Pb} / \mathrm{Ce}[39]$ that are instead relatively constant through time (Supplementary Figure 8). If increasing magma fractionation (3) was used to account for the entire observed trend, this would imply that modern basalts are on average created through fractionation of very high $\mathrm{MgO}$ magmas such as komatiites, which is clearly not the case. Indeed, if anything, a thick Archean crust as suggested by crustal depth-ofmelting/fractionation indicators (Figure 2) as well as rapidly-cooling high-Mg mafic magmas suggest increased fractional crystallization in the Archean, in opposition to the observed trend. To address the issue more quantitatively, we mimic the approach of Klein and Langmuir [40], by applying our bootstrap resampling approach to reconstruct global mean $\mathrm{MgO}-\mathrm{Na}_{2} \mathrm{O}$ and $\mathrm{MgO}-\mathrm{CaO} / \mathrm{Al}_{2} \mathrm{O}_{3}$ trends for time periods between the Archean and the present day (Supplementary Figure 9). Both trends are consistent with globally averaged fractionation paths, illustrating that substantial fractionation occurs at any given time, but parallel trends are shifted as a function of age. Following Klein and Langmuir [40], these parallel trends illustrate changes in mantle melt fraction. Given that decreasing average mantle melt fraction through time (4) is then the most compatible interpretation of the data, we are faced with two options: secular cooling or mantle dehydration. Evidence for a more hydrous Archean mantle is equivocal [41], and it has even been argued that the potentially undercompensated flux of water into the mantle at subduction zones suggests that the hydration state of the mantle is increasing through time, not decreasing [42, 43]. Secular cooling, on the other hand, presents no such caveats and is widely expected on the basis of physical constraints.

Mantle percent melt was estimated for each sample from $43-51 \% \mathrm{SiO}_{2}$ in all 10,000 simulations by numerical least squares optimization of the simulated major element data to that of slightly hydrous $(0.1 \%)$ primitive mantle partial melts as calculated by MELTS $[15,16]$ for isobaric melting at a range of pressure conditions. Resulting percent melt estimates were found to agree within error despite order of magnitude differences in melting pressure (Supplementary Figure 10), suggesting that the results are insensitive to changes in model pressure. Although MELTS does not extend to high enough pressures to directly simulate high-degree isentropic decompression melting, as long as the system is not far from equilibrium, percent melt and melt composition will be roughly state functions of pressure and temperature - that is, path independent. Consequently, at a given pressure (say, corresponding to the base of the crust) percent melt and melt composition will both be state functions of temperature. In this case, then, there will be a simple relationship between percent melt and melt composition, allowing for accurate estimation of percent melt from melt composition regardless of the exact melting path. This approach will break down in the case of fractional melt extraction, in which the melt cannot be in equilibrium with the solid; the absolute value of the results may therefore be inaccurate in the case of predominantly fractional melting, though relative trends would be expected to remain robust.

Since our analysis focuses on the trends in melt percentage over Earth history rather than the absolute values of these estimates, a number of sources of systematic error can be disregarded. We have intentionally not corrected basalt major element compositions for fractional crystallization to calculate primary melt compositions, as such an analysis has already been conducted on smaller datasets, and is only amenable to a small proportion of the available data [44]. By neglecting the effect of fractional crystallization, our estimates of percent melting through time are systematic underestimates. Nonetheless, absent major changes in the degree of fractional crystallization through time as is argued above, the results should accurately represent changes in percent melt over time. Herzberg et al. [44] analyzed a database of $(n \approx 1500)$ basalts through early Earth history, identified those that could be corrected to primary mantle melts $(n=33)$ to extract mantle potential temperature. The topology of a temperature curve corresponding to our degree-melting curve (Figure 1f) agrees well with Herzberg et al. [44]'s mantle potential temperature, though as expected they obtain higher mantle temperatures [44]. Further, our percent melting results generally agree with independent estimates of modern and Archean percent melting, suggesting that the degree of underestimation is not large [45, 17].

In order to determine if observed trends in trace element ratios such as $\mathrm{La} / \mathrm{Yb}$ in low silica samples could be generated solely by a single set of bulk partition coefficients given the estimated percent melting curve, linearized least squares regression was used to optimize bulk partition coefficients to fit percent melting and trace element curves with analytical non-modal batch melting equations. No single set of partition coefficients can reproduce the observed trace element ratios in basalts by varying melt fraction alone, showing that other variables such as temperature and mineralogy may have influenced partition coefficients, or that significant changes in source trace element composition (e.g., for the example of an arc setting, change in the trace element composition of the mantle wedge due to subduction erosion or sediment subduction) had an effect.

\subsection{Redox partitioning calculations}

To assess the potential for magmatic redox partitioning to affect surficial redox state, a simple stoichiometric redox balance of mantle restite was calculated for a modest $5 \mathrm{~km} 3 / \mathrm{yr}$ magmatic flux (equivalent to estimates of modern arc magmatism; e.g., Crisp, 1984), assuming a magma density of $2500 \mathrm{~kg} / \mathrm{m} 3,6$ weight percent restitic Fe, and a ratio of $2 \mathrm{~kg}$ of restite to $1 \mathrm{~kg}$ of magma, as follows:

$$
\begin{aligned}
& \frac{5 \mathrm{~km}^{3} \text { magma }}{\mathrm{yr}} * \frac{1000^{3} \mathrm{~m}^{3}}{\mathrm{~km}^{3}} * \frac{2500 \mathrm{~kg}}{\mathrm{~m}^{3}} * \frac{2 \mathrm{~kg} \text { restite }}{\mathrm{kg} \mathrm{magma}} \ldots \\
& \cdots * \frac{0.06 \mathrm{~kg} \mathrm{Fe}}{\mathrm{kg} \mathrm{restite}} * \frac{1000 \mathrm{~g}}{\mathrm{~kg}} * \frac{1 \mathrm{~mol} \mathrm{Fe}}{55.85 \mathrm{~g} \mathrm{Fe}}=\frac{2.68 * 10^{13} \mathrm{~mol} \mathrm{Fe}}{\mathrm{yr}}
\end{aligned}
$$

Consequently, a fifteen percent increase in $\mathrm{Fe}^{3+} / \Sigma \mathrm{Fe}$ of this restitic flux would liberate $4.02 * 10^{12} \mathrm{~mol} e^{-}$per year, or, stoichiometrically, consume $1.0 * 10^{12} \mathrm{~mol} \mathrm{O}_{2} / \mathrm{yr}$ - similar in magnitude to estimates of 
the entire present-day volcanic volatile flux of $\sim 5.6 * 10^{12} \mathrm{~mol} e^{-} / \mathrm{yr}$ [46].

Notably, the $\mathrm{Fe}^{3+} / \mathrm{Fe}^{2+}$ ratio of many magmas is low even at the present day, apparently not leaving much room for variation through time. However, theory and experiment suggest that oxygen fugacity is roughly proportional to the fourth power of ferric/ferrous ratio [47]. Consequently, a change in ferric/ferrous ratio from 0.1 to 0.01 would result in a roughly ten order of magnitude decrease in magmatic oxygen fugacity, with potentially major consequences for the production of volcanic volatiles.

\section{AUTHOR CONTRIBUTIONS}

Both authors interpreted the results and prepared the manuscript. C.B.K. compiled the data set and performed the calculations.

\section{AcKNOWLEDGEMENTS}

We thank K. Condie and J.-F. Moyen for providing their data sets of granitoid rocks through time; F. Simons for assistance with statistical methods; C.-T. Lee, W. Fischer, A. Maloof, C. Langmuir, O. Müntener, J. Higgins, A. Rubin, T. Duffy, K. Samperton, and B. Dyer for discussions; and W. White for comments. C.B.K. was supported by a Princeton University Centennial Fellowship

\section{Data Availability}

All data and source code used in this study is freely available at https : //github.com/brenhinkeller/StatisticalGeochemistry.

\section{REFERENCES}

[1] Claude Herzberg, Paul D Asimow, Nicholas T Arndt, Yaoling Niu, C M Lesher, J G Fitton, M J Cheadle, and A D Saunders. Temperatures in ambient mantle and plumes: Constraints from basalts, picrites, and komatiites. Geochemistry Geophysics Geosystems, 8(2), 2007.

[2] Christopher J Hawkesworth and A I S Kemp. Evolution of the continental crust. Nature, 433:811-817, 2006.

[3] Kent C Condie and Craig O'Neill. The ArcheanProterozoic boundary: 500 my of tectonic transition in Earth history. American Journal of Science, 310:775-790, 2010.

[4] Jean-François Moyen. The composite Archaean grey gneisses: Petrological significance, and evidence for a non-unique tectonic setting for Archaean crustal growth. LITHOS, 123(1-4):21-36, 2010.

[5] Irina M Artemieva. Global 1CE 1 thermal model TC1 for the continental lithosphere: implications for lithosphere secular evolution. Tectonophysics, 416:245-277, 2006.

[6] Raymond J Durrheim and Walter D Mooney. Archean and Proterozoic crustal evolution: evidence from crustal seismology. Geology, 19:606-609, 1991.

[7] Lee R Kump. The rise of atmospheric oxygen. Nature, 451:277-278, 2008.

[8] KamLAND Collaboration. Partial radiogenic heat model for Earth revealed by geoneutrino measurements. Nature Geoscience, 4(9):647-651, July 2011.
[9] K C Condie and V Pease. When Did Plate Tectonics Begin on Planet Earth? - Google Books, 2008.

[10] Maarten J de Wit. On Archean granites, greenstones, cratons and tectonics: does the evidence demand a verdict? Precambrian Research, 91:181-226, 1998.

[11] Kent C Condie. Did the character of subduction change at the end of the Archean? Constraints from convergentmargin granitoids. Geology, 36(8):611-614, 2008.

[12] Zheng-Xue Anse Li and Cin-Ty Aeolus Lee. The constancy of upper mantle fO2 through time inferred from $\mathrm{V} / \mathrm{Sc}$ ratios in basalts. Earth and Planetary Science Letters, 228:483-493, 2004.

[13] EarthChem. EarthChem Portal, January 2010. URL http: //www . earthchem.org/.

[14] C Bassin, G Laske, and G Masters. The Current Limits of resolution for surface wave tomography in North America. EOS Trans. AGU., 81:F897, 2000.

[15] Mark S Ghiorso and Richard O Sack. Chemical mass transfer in magmatic processes IV. A revised and internally consistent thermodynamic model for the interpolation and extrapolation of liquid-solid equilibria in magmatic systems at elevated temperatures and pressures. Contributions to Mineralogy and Petrology, 119(2-3): 197-212, March 1995.

[16] Paul D Asimow and Mark S Ghiorso. Algorithmic modifications extending MELTS to calculate subsolidus phase relations. American Mineralogist, 83:1127-1132, 1998.

[17] Michael J Walter. Melting of garnet peridotite and the origin of komatiite and depleted lithosphere. Journal of Petrology, 39(1):29-60, 1998.

[18] Marc M Hirschmann, Mark S Ghiorso, L E Wasylenki, Paul D Asimow, and Edward M Stolper. Calculation of Peridotite Partial Melting from Thermodynamic Models of Minerals and Melts. I. Review of Methods and Comparison with Experiments. Journal of Petrology, 39(6): 1091-1115, 1998.

[19] Mark S Drummond and Marc J Defant. A model for trondhjemite-tonalite-dacite genesis and crustal growth via slab melting: Archean to modern comparisons. Journal of Geophysical Research, 95(B13):21503-21521, December 1990.

[20] Jean-François Moyen and Gary Stevens. Experimental Constraints on TTG Petrogenesis: Implications for Archean Geodynamics. Archean Geodynamics and Environment Geophysical Monograph Series, 164:147-175, 2006.

[21] Nick Petford and M Atherton. Na-rich partial melts from newly underplated basaltic crust: the Cordillera Blanca Batholith, Peru. Journal of Petrology, 37(6):1491-1521, 1996.

[22] Othmar Müntener, Peter B Kelemen, and Timothy L Grove. The role of $\mathrm{H} 2 \mathrm{O}$ during crystallization of primitive arc magmas under uppermost mantle conditions and genesis of igneous pyroxenites: an experimental study. Contributions to Mineralogy and Petrology, 141(6):643-658, September 2001. 
[23] Robert Woodbury Kay and Suzanne Mahlburg Kay. Delamination and delamination magmatism. Tectonophysics, 219:177-189, 1993.

[24] Jean H Bédard. A catalytic delamination-driven model for coupled genesis of Archaean crust and sub-continental lithospheric mantle. Geochimica et Cosmochimica Acta, 70:1188-1214, 2006.

[25] James Farquhar, Huiming Bao, and Mark Thiemens. atmospheric influence of earth's earliest sulfur cycle. Science, 289:756-758, 2000.

[26] Woodward W Fischer and Andrew H Knoll. An iron shuttle for deepwater silica in Late Archean and early Paleoproterozoic iron formation. GSA Bulletin, 121(1-2):222235, 2009.

[27] Rob Rye and Heinrich D Holland. Paleosols and the evolution of atmospheric oxygen: a critical review. American Journal of Science, 298:621-672, 1998.

[28] Birger Rasmussen and Roger Buick. Redox state of the Archean atmosphere: Evidence from detrital heavy minerals in ca. 3250-2750 Ma sandstones from the Pilbara Craton, Australia. Geology, 27(2):115-118, 1999.

[29] J F Kasting, D Eggler, and S Raeburn. Mantle redox evolution and the oxidation state of the Archean atmosphere. The Journal of Geology, 101:254-257, 1993.

[30] Lee R Kump and Mark E Barley. Increased subaerial volcanism and the rise of atmospheric oxygen 2.5 billion years ago. Nature, 448:1033-1036, 2007.

[31] Cin-Ty Aeolus Lee, Peter Luffi, Véronique Le Roux, Rajdeep Dasgupta, F Albaréde, and William P Leeman. The redox state of arc mantle using $\mathrm{Zn} / \mathrm{Fe}$ systematics. Nature, 468:681-685, 2010 .

[32] Dante Canil, Hugh St C O'Neill, D Graham Pearson, Roberta L Rudnick, William F McDonough, and D A Carswell. Ferric iron in peridotites and mantle oxidation states. Earth and Planetary Science Letters, 123:205-220, 1994.

[33] P Van Aken and B Liebscher. Quantification of ferrous/ferric ratios in minerals: new evaluation schemes of Fe L 23 electron energy-loss near-edge spectra. Physics and Chemistry of Minerals, 29:188-200, 2002.

[34] Makoto Matsumoto and Takuji Nishimura. Mersenne twister: a 623-dimensionally equidistributed uniform pseudo-random number generator. ACM Transactions on Modelling and Computer Simulation, 8(1):3-30, January 1998.

[35] Kent C Condie, M E Bickford, Richard C Aster, Elena Belousova, and David W Scholl. Episodic zircon ages, Hf isotopic composition, and the preservation rate of continental crust. GSA Bulletin, 123:951-957, 2011.

[36] Kent C Condie and Richard C Aster. Episodic zircon age spectra of orogenic granitoids: The supercontinent connection and continental growth. Precambrian Research, 180:227-236, 2010.

[37] William M White and Albrecht W Hofmann. Sr and Nd isotope geochemistry of oceanic basalts and mantle evolution. Nature, 296:821-825, April 1982.
[38] Jeff D Vervoort and Janne Blichert-Toft. Evolution of the depleted mantle: Hf isotope evidence from juvenile rocks through time. Geochimica et Cosmochimica Acta, 63(34):533-556, February 1999.

[39] Albrecht W Hofmann, K P Jochum, M Seufert, and William $\mathrm{M}$ White. $\mathrm{Nb}$ and $\mathrm{Pb}$ in oceanic basalts: new constraints on mantle evolution. Earth and Planetary Science Letters, 79(1-2):33-45, August 1986.

[40] E M Klein and Charles H Langmuir. Global correlations of ocean ridge basalt chemistry with axial depth and crustal thickness. Journal of Geophysical Research, 92 (B8):8096-8115, 1987.

[41] Andrew J Berry, Leonid V Danyushevsky, Hugh St C O’Neill, Matt Newville, and Stephen R Sutton. Oxidation state of iron in komatiitic melt inclusions indicates hot Archaean mantle. Nature, 455:960-963, 2008.

[42] Simon M Peacock. Fluid Processes in Subduction Zones. Science, 248:329-337, April 1990.

[43] Shigenori Maruyama and Kazuaki Okamoto. Water transportation from the subducting slab into the mantle transition zone. Gondwana Research, 11(1-2):148-165, January 2007.

[44] Claude Herzberg, Kent C Condie, and Jun Korenaga. Thermal history of the Earth and its petrological expression. Earth and Planetary Science Letters, 292:79-88, 2010.

[45] Michael J Walter. Melt Extraction and Compositional Variability in Mantle Lithosphere. In Treatise on Geochemistry, pages 363-394. Elsevier, 2003.

[46] Lee R Kump, J F Kasting, and Mark E Barley. Rise of atmospheric oxygen and the "upside-down" Archean mantle. Geochemistry Geophysics Geosystems, 2, 2001.

[47] G S Nikolaev, A A Borisov, and A A Ariskin. Calculation of the ferric-ferrous ratio in magmatic melts: testing and additional calibration of empirical equations for various magmatic series. Geochemistry International, 34(9):641649, 1996. 

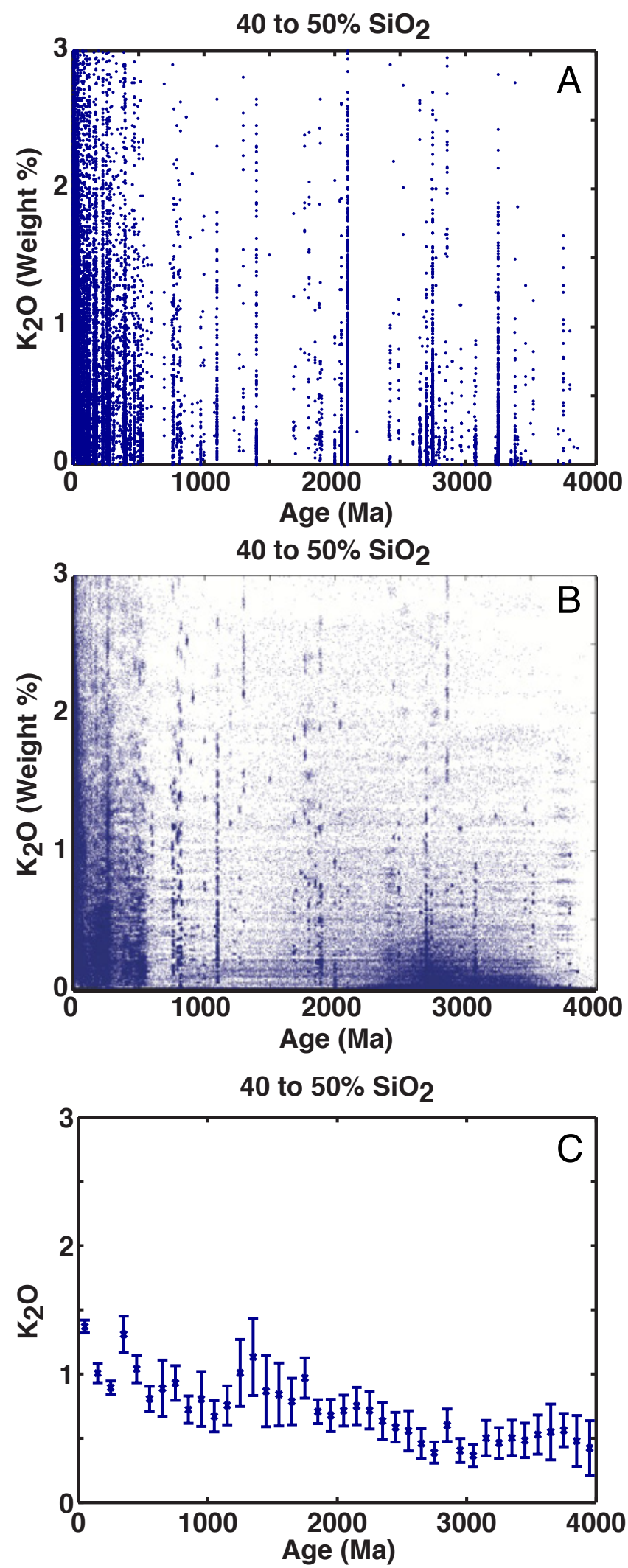

Supplementary Figure 1: Schematic illustration of Monte Carlo analysis for the example case of $\mathrm{K}_{2} \mathrm{O}$. (a) raw data; (b) results of 71 out of 10,000 weighted bootstrap-resampling Monte Carlo simulations, illustrating peak smearing due to uncertainties in reported sample ages; (c) sample means with $2 \sigma$ standard errors of the mean. Note that figures are cropped at 3 wt. \% $\mathrm{K}_{2} \mathrm{O}$ but the averages shown in (c) are calculated from the full dataset. 

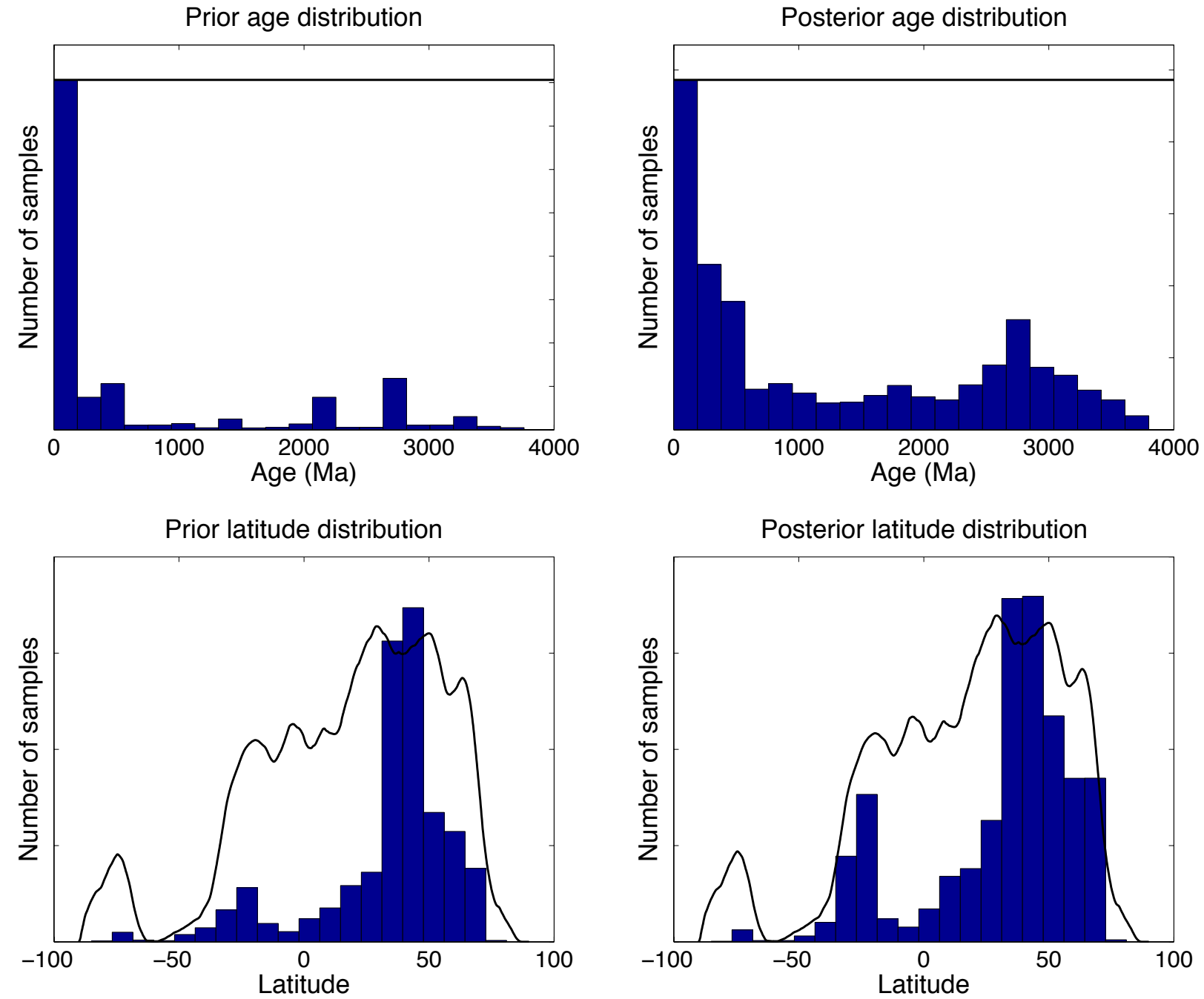

Prior longitude distribution
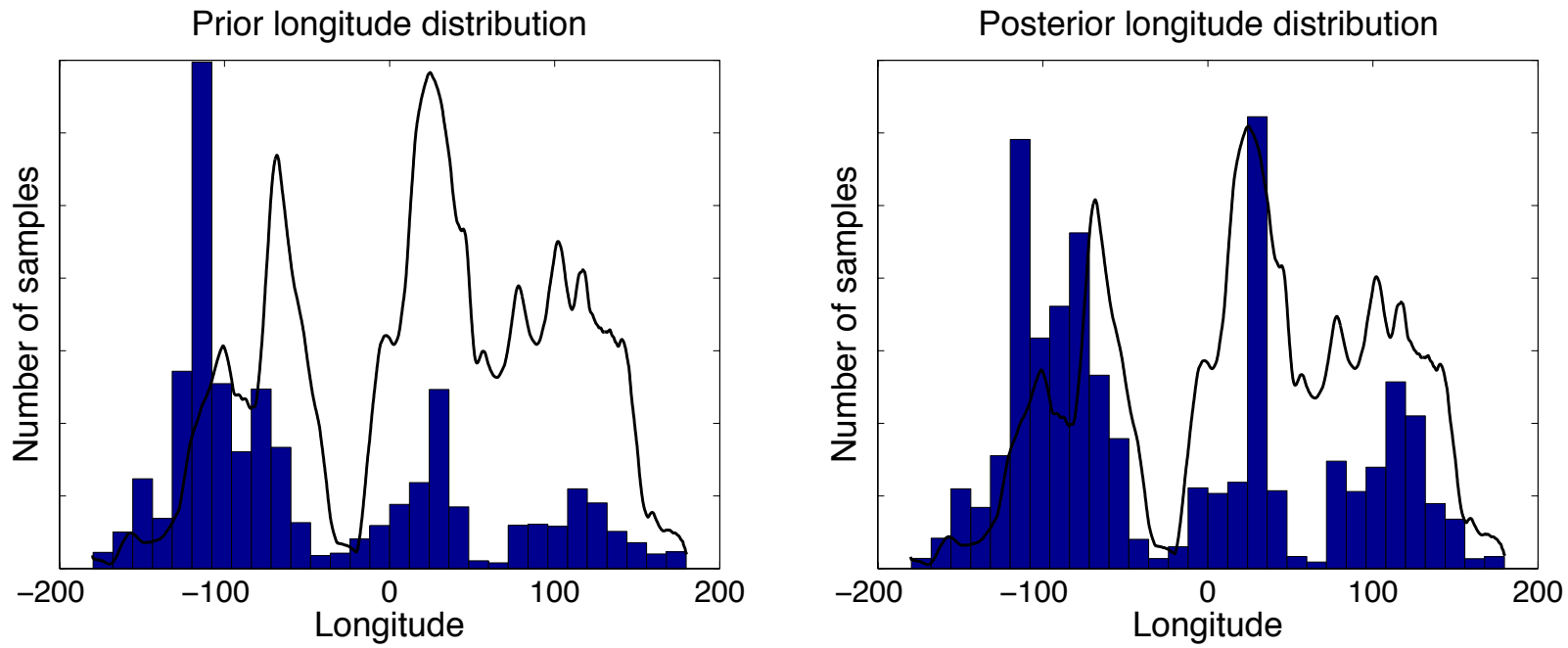

Supplementary Figure 2: Prior (original data; left) and posterior (after Monte-Carlo analysis; right) sampling distributions (histograms) compared to ideal distributions (solid lines), where the ideal spatial distributions are based on the current exposed area of the continents. Scale of the ideal curve is normalized to the height of the highest peak in the distribution for both the prior (raw data) and posterior (resampled data) cases. Since the true value of age distribution is unknown, no curve is shown for comparison. Instead, one sees that undersampled age ranges increase in importance during Monte Carlo simulation. 
Distribution of the Mean

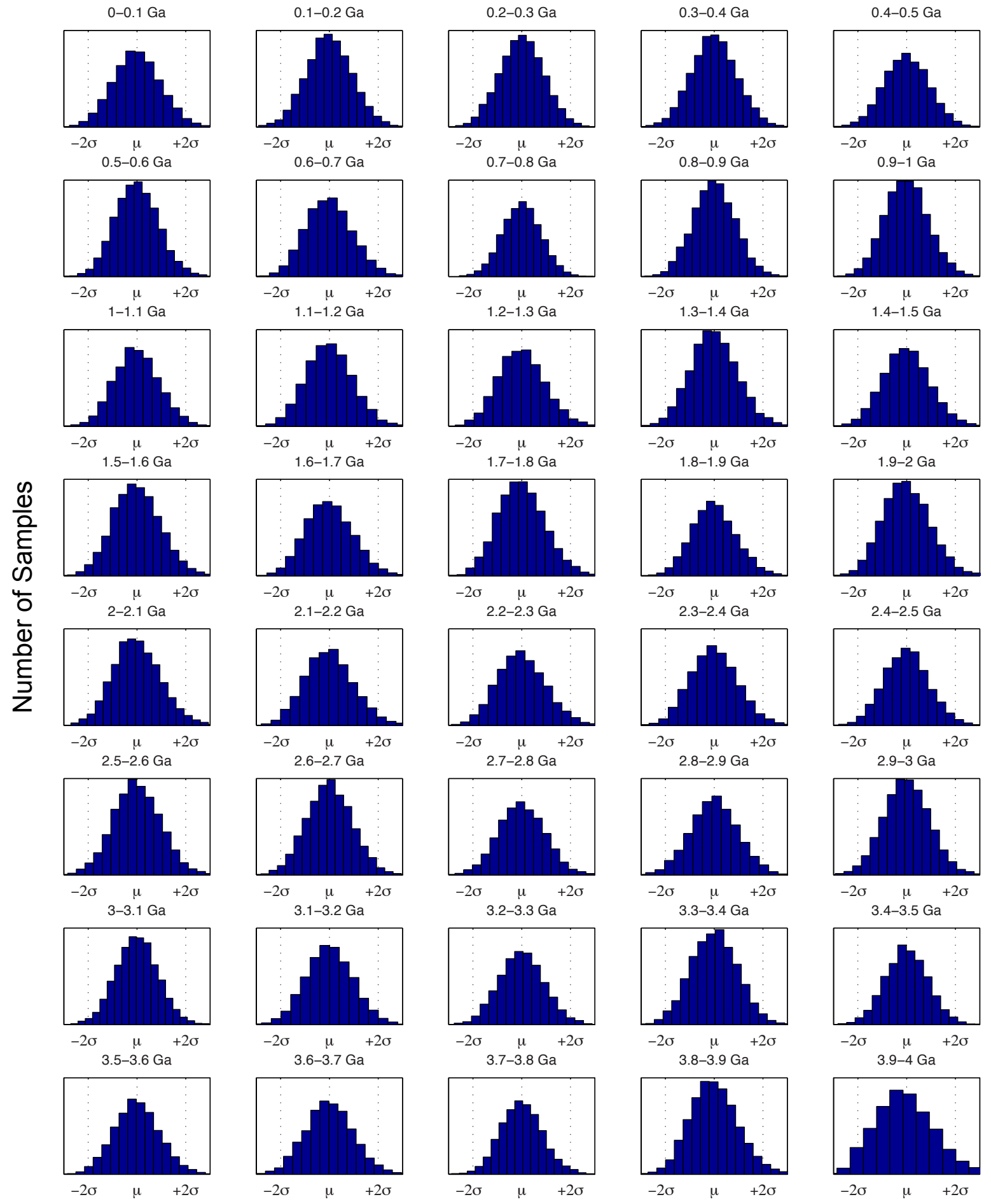

Supplementary Figure 3: Histograms of the estimated mean $\mathrm{MgO}$ content of $43-51 \% \mathrm{SiO}_{2}$ samples in each of $10,000 \mathrm{Monte}$ Carlo simulations for each 100 Ma bin between 0 and $4 \mathrm{Ga}$, illustrating the approximately Gaussian distribution of the means. 


\section{Response of Monte Carlo simulation to choice of uncertainty distribution}

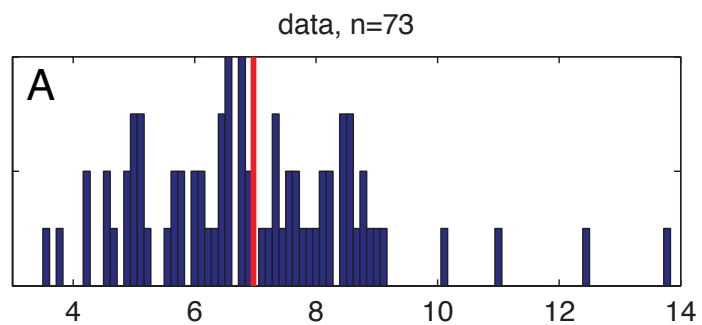

Monte Carlo simulation using Gaussian distribution

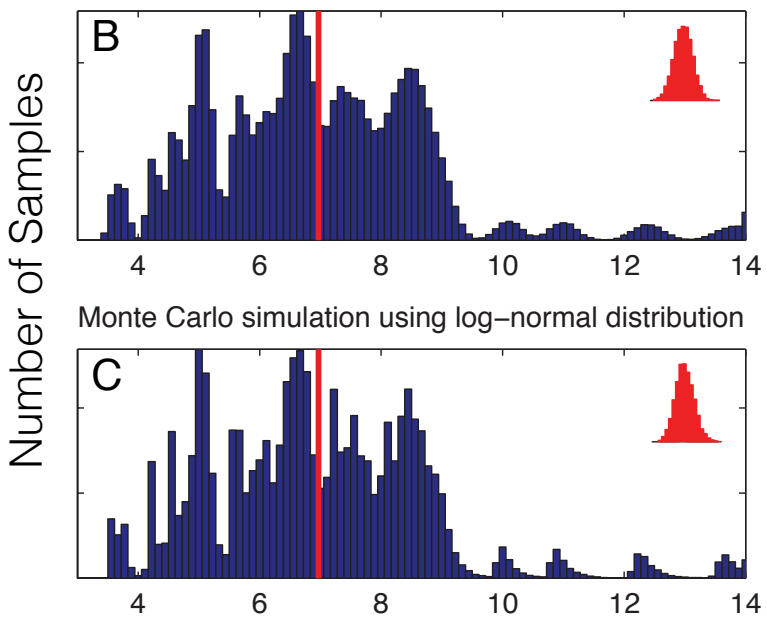

Monte Carlo simulation using chi-squared distribution

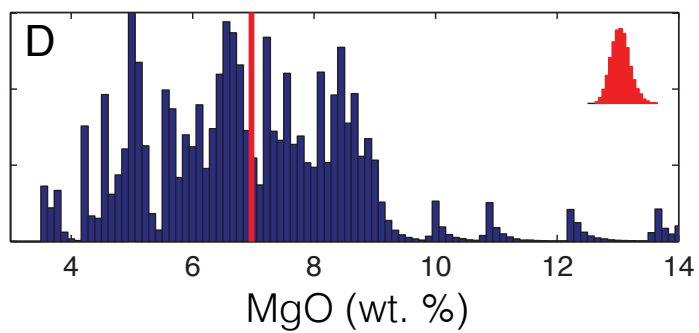

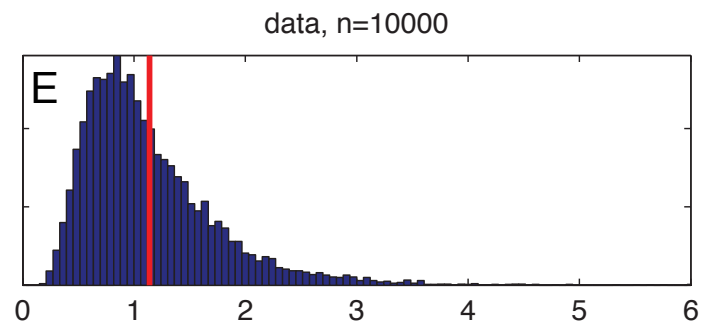

Monte Carlo simulation using Gaussian distribution

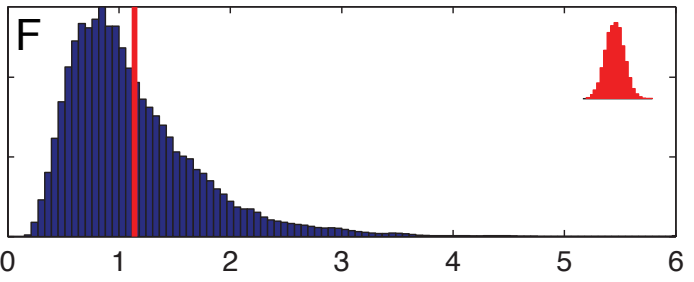

Monte Carlo simulation using log-normal distribution

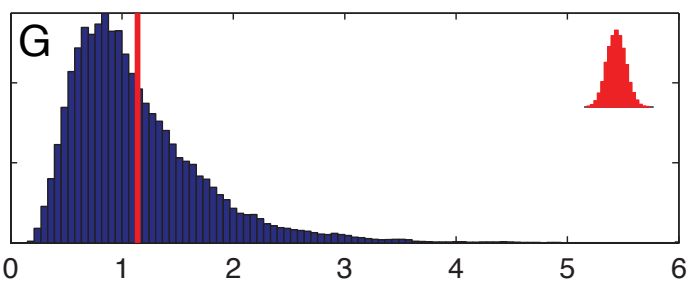

Monte Carlo simulation using chi-squared distribution

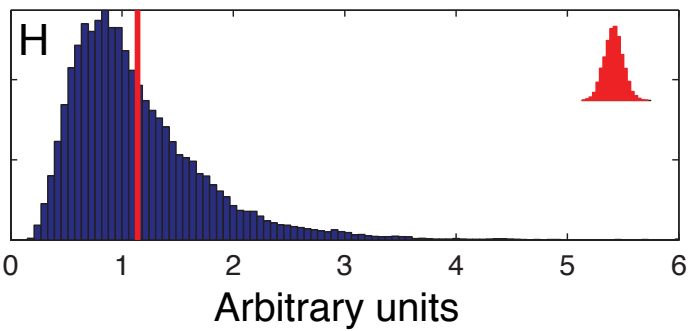

Supplementary Figure 4: The results of Monte Carlo simulation of (1) MgO content of mafic igneous samples between 400 and $410 \mathrm{Ma}$ (left, a-d), and (2) synthetic lognormal distribution with location parameter 0 and variance parameter 0.5 (right, e-h), where $4 \%(2 \sigma)$ analytical uncertainty is simulated using three different distributions for the analytical error. (a,e): distribution of the raw data; (b,f): distribution of Monte Carlo results when a Gaussian error distribution is used; (c,g): distribution of results when a log-normal distribution is used; $(\mathbf{d}, \mathbf{h})$ : distribution of results when a chi-squared distribution is used. Red vertical lines show the position of the mean for each set of results; inset illustrates the distribution of individual means about that line (not to scale). 
Gaussian age uncertainty and geochemical uncertainty

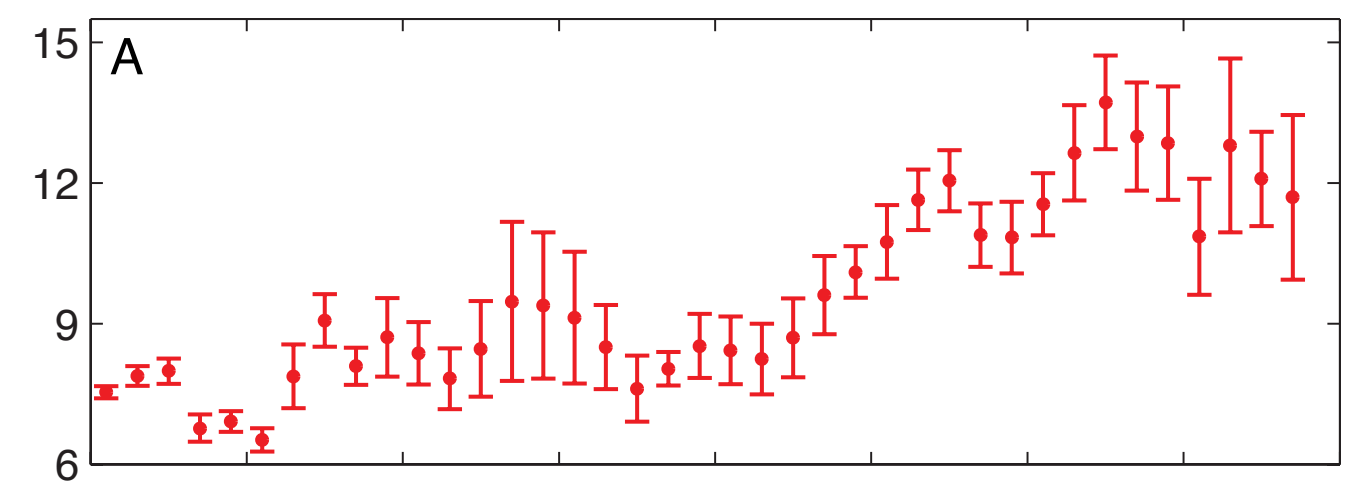

Gaussian age uncertainty and log-normal geochemical uncertainty

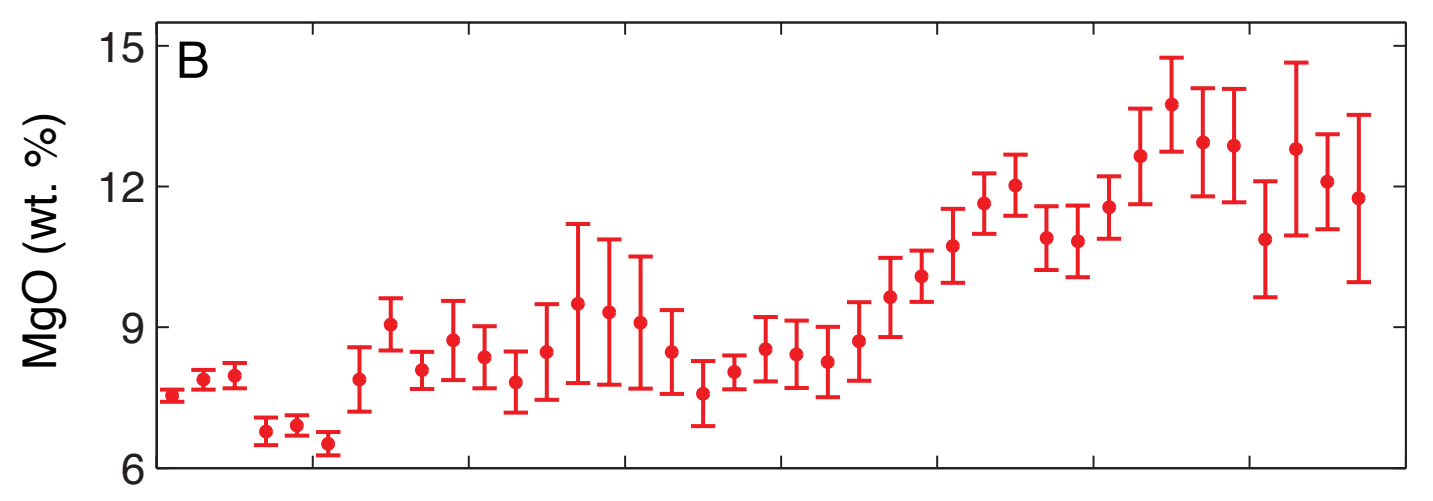

Log-normal age uncertainty and geochemical uncertainty

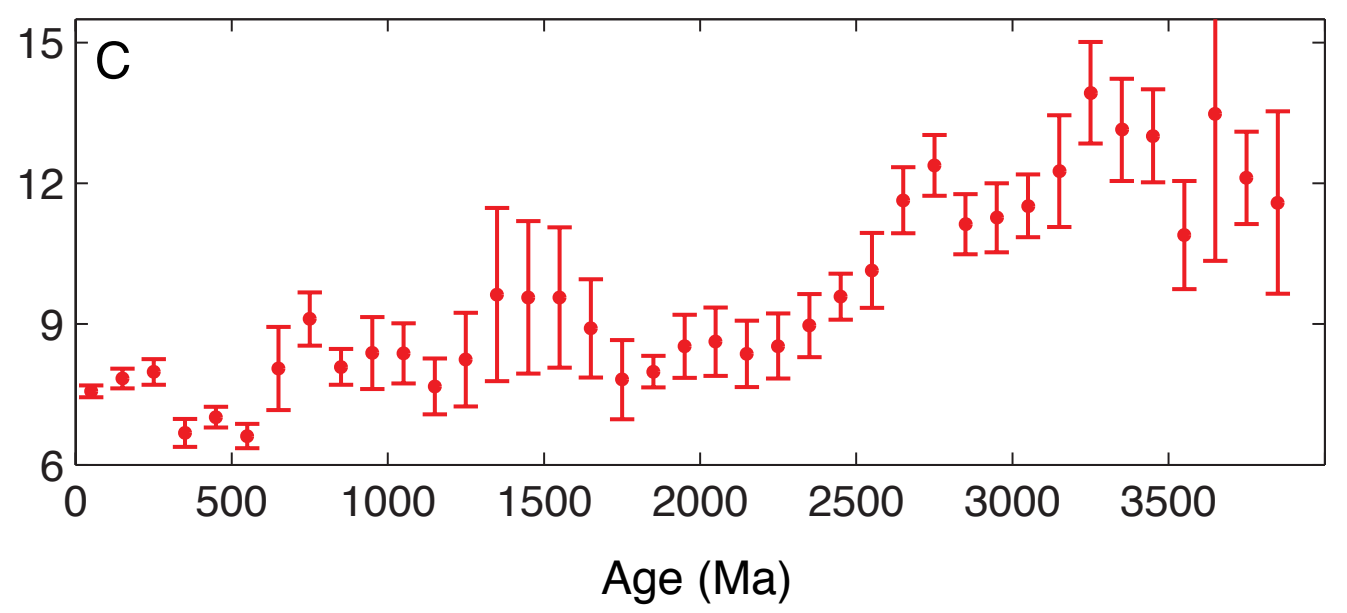

Supplementary Figure 5: Monte Carlo simulation of $\mathrm{MgO}$ content through time in mafic (43-51\% $\left.\mathrm{SiO}_{2}\right)$ samples using (a) a Gaussian distribution for both geochemical error and geochronological error (as in Figures 1-3); (b) a Gaussian distribution for geochronological error and a log-normal distribution for geochemical error; and (c) a log-normal distribution for both geochemical error and geochronological error. 

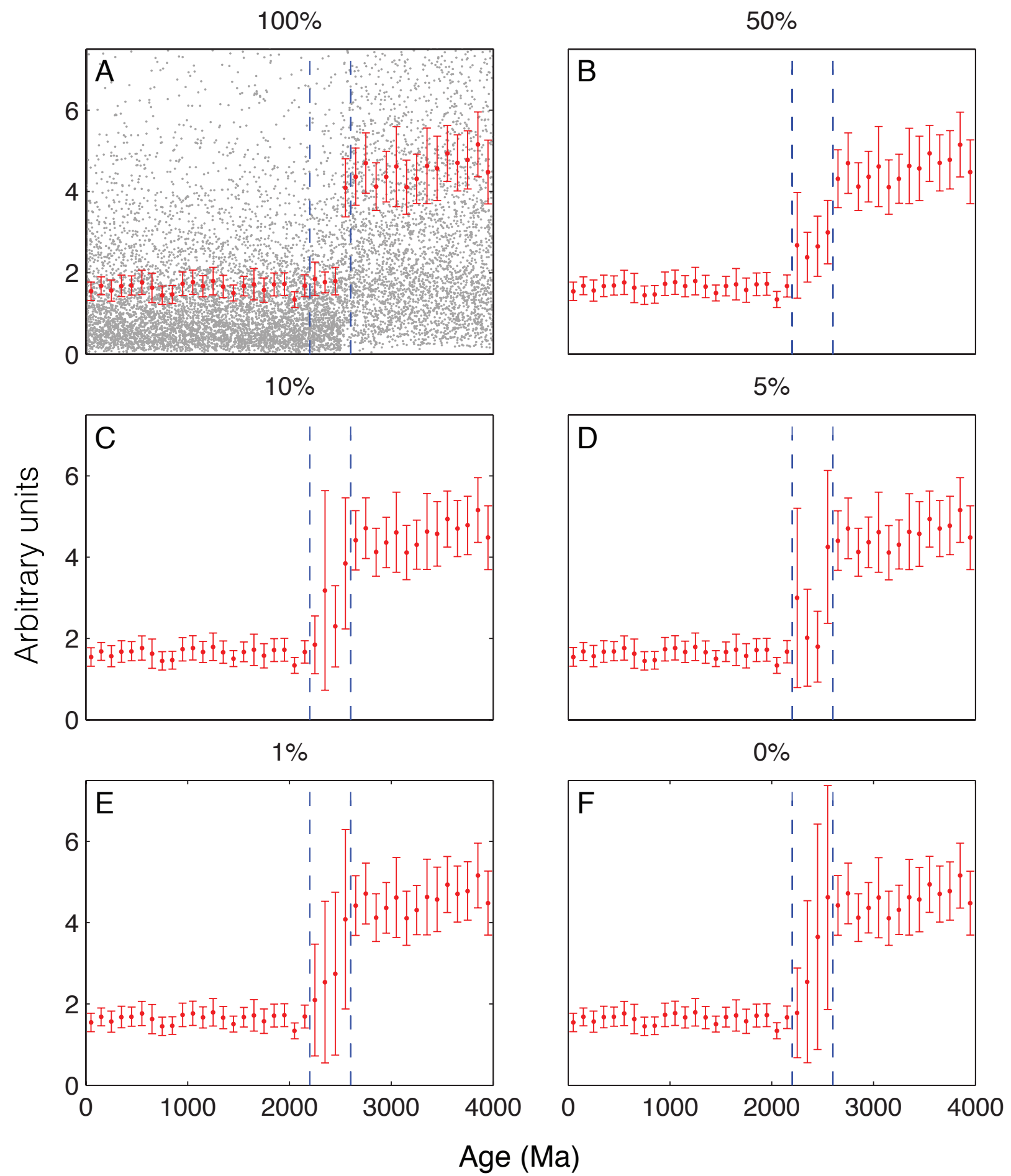

Supplementary Figure 6: Monte Carlo analysis of simulated dataset with an abrupt change in mean and variance at $2500 \mathrm{Ma}$ under the influence of varying degrees of data loss between 2200 and $2600 \mathrm{Ma}$ (dashed blue lines) ranging from $100 \%$ of data preserved (a) to all data deleted (f). Background of plot (a) shows the initial synthetic dataset (note that data is cropped by the range of the plot). Note that in the case of a complete lack of input data between 2200 and $2600 \mathrm{Ma}(0 \%)$, output data is only defined due to the age uncertainty of the adjacent input data. 


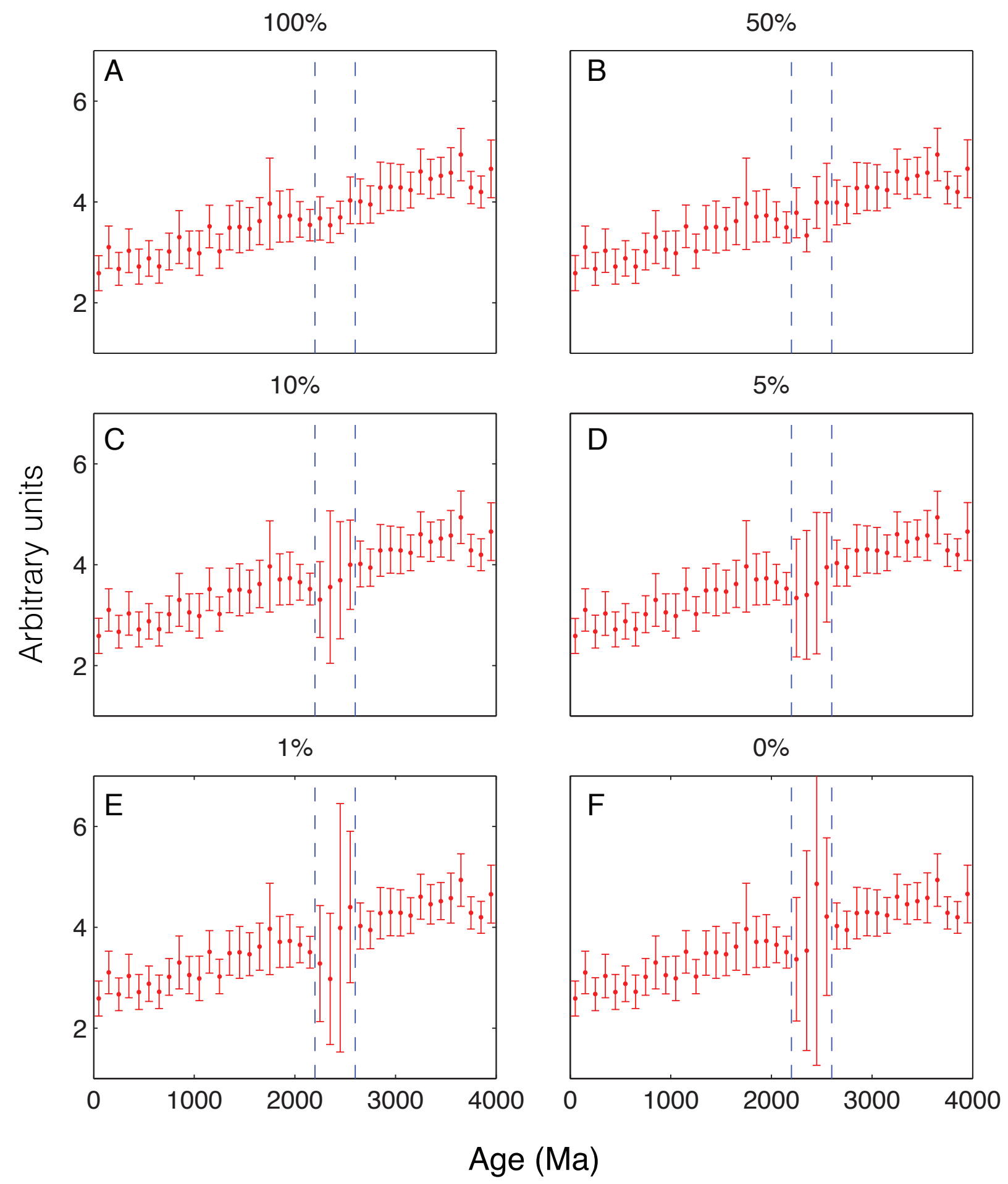

Supplementary Figure 7: Monte Carlo analysis of simulated dataset under the influence of varying degrees of data loss between 2200 and $2600 \mathrm{Ma}$ (dashed blue lines) ranging from 100\% of data preserved (a) to all data deleted (f) as in Figure 6, but with linear instead of stepwise trend in the initial simulated dataset. Note that in the case of a complete lack of input data between 2200 and $2600 \mathrm{Ma}(0 \%)$, output data is only defined due to the age uncertainty of the adjacent input data. 

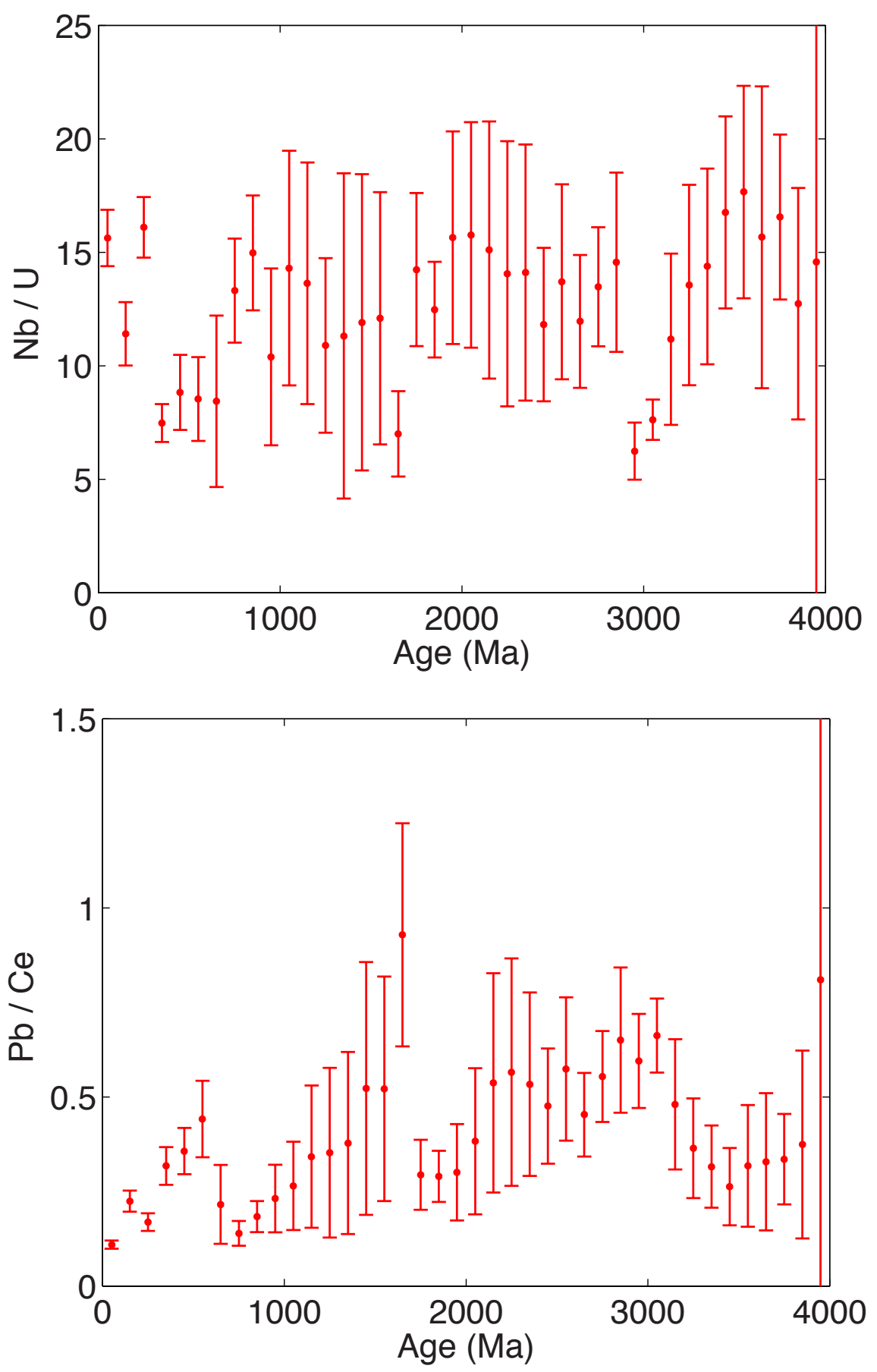

Supplementary Figure 8: Mean $\mathrm{Pb} / \mathrm{Ce}$ and $\mathrm{Nb} / \mathrm{U}$ through time for mafic lithologies, illustrating the lack of a clear trend that would be required to explain observed trends in compatible and incompatible element concentration through changes in degree of crustal contamination through time. Error bars represent $2 \sigma$ standard errors of the mean from Monte-Carlo bootstrap resampling. 


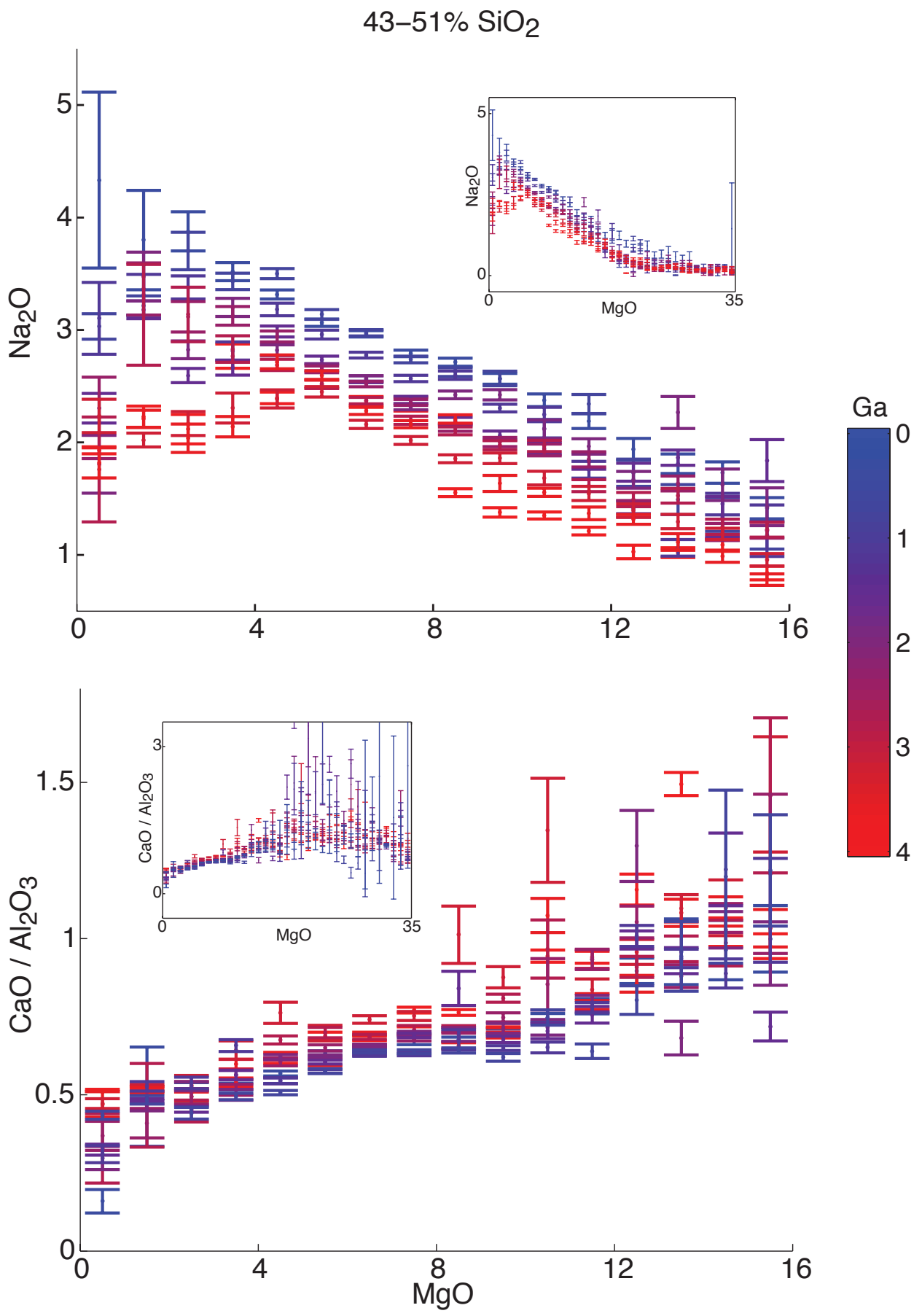

Supplementary Figure 9: Secular evolution of basalt fractionation trends through time, following an approach modified from Klein and Langmuir14 for (a) $\mathrm{Na}_{2} \mathrm{O}$ vs $\mathrm{MgO}$ and (b) $\mathrm{CaO} / \mathrm{Al}_{2} \mathrm{O}_{3}$ vs $\mathrm{MgO}$. Each color illustrates a bootstrap-resampling Monte Carlo estimate of global mean $\mathrm{Na}_{2} \mathrm{O}$ and $\mathrm{CaO} / \mathrm{Al}_{2} \mathrm{O}_{3}$ at a given $\mathrm{MgO}$ range during a different a $400 \mathrm{Ma}$ time interval between the present (blue) and $4 \mathrm{Ga}$ (red). Inset shows the full range of the plot.Trends within a particular time interval are interpreted to approximate a globally averaged liquid line of descent for that time period; the parallel fractionation trends showing an increase in $\mathrm{Na}_{2} \mathrm{O}$ and decrease in $\mathrm{CaO} / \mathrm{Al}_{2} \mathrm{O}_{3}$ with time for given $\mathrm{MgO}$ demonstrate decreasing mantle melt fraction for a given time period. It may be noteworthy that the evolution of $\mathrm{Na}_{2} \mathrm{O}$ values through time at $8 \% \mathrm{MgO}$ (i.e., $\mathrm{Na}_{8.0}$ ) corresponds closely to the evolution of mean $\mathrm{Na}_{2} \mathrm{O}$ through time in Figure 1. 

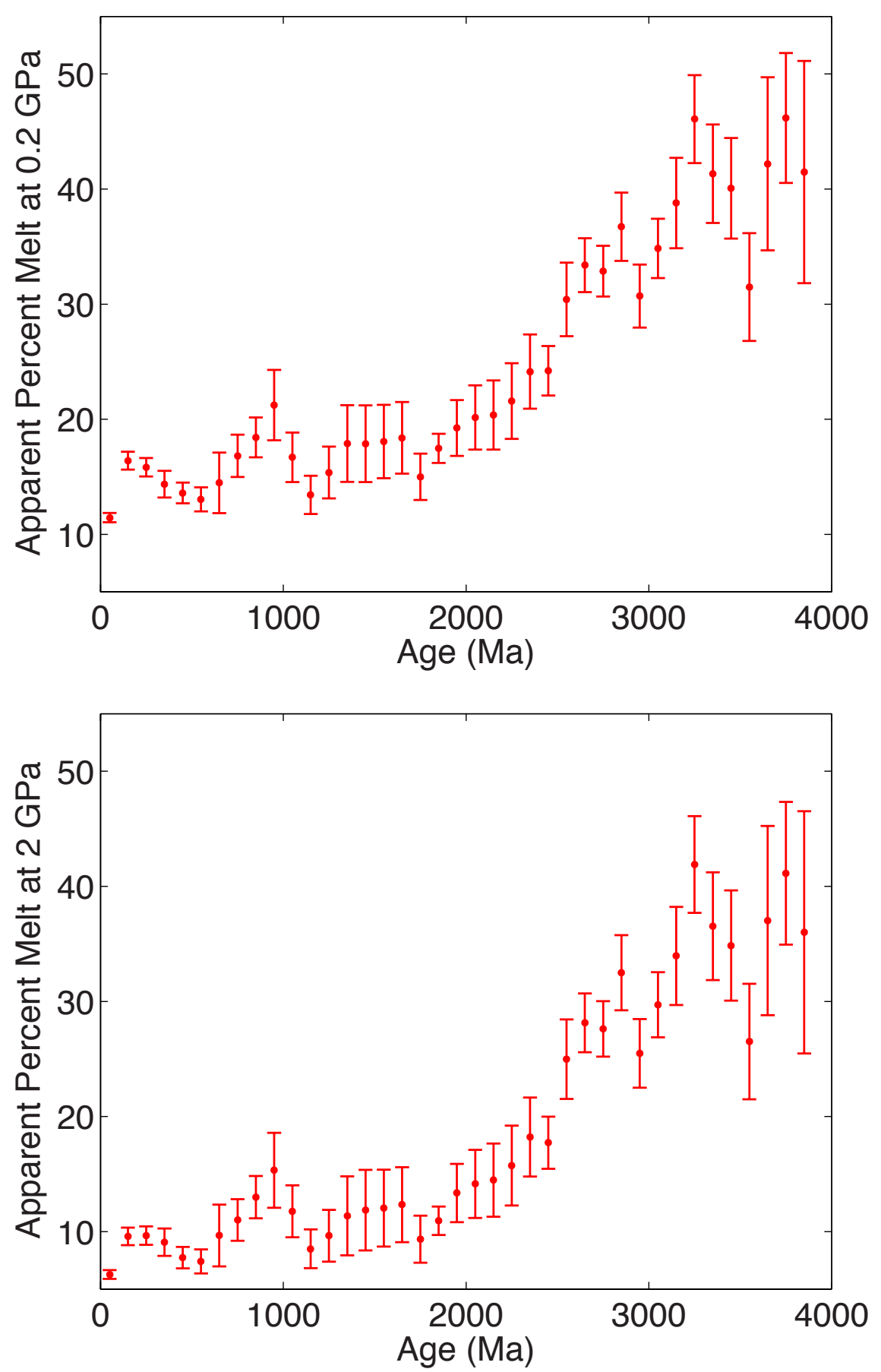

Supplementary Figure 10: Estimated percent mantle melt from 43-51\% $\mathrm{SiO}_{2}$ samples at (a) $0.2 \mathrm{GPa}$ and (b) $2 \mathrm{GPa}$. Error bars are $2 \sigma$ standard errors of the mean. 


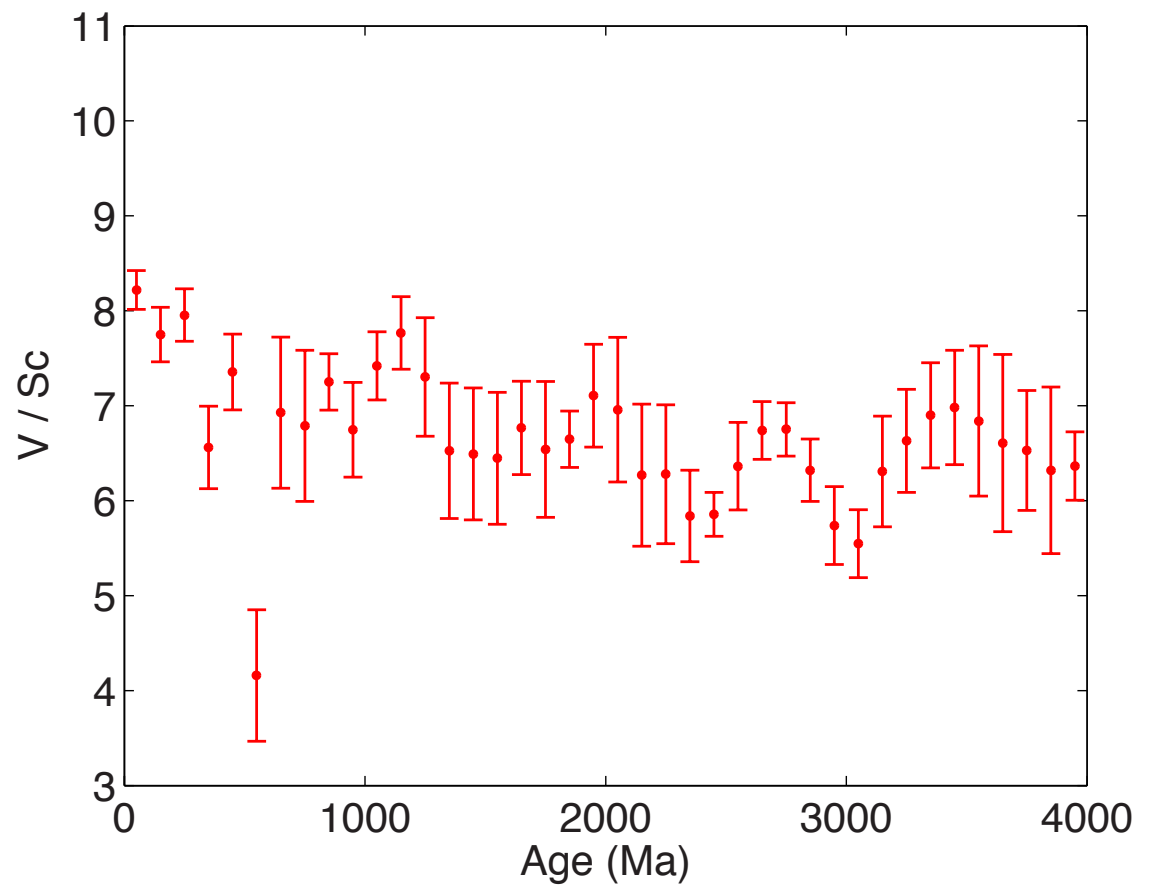

Supplementary Figure 11: Mean V/Sc ratio through time for mafic (43-51\% $\left.\mathrm{SiO}_{2}\right)$ samples, illustrating the lack of a visible trend that would indicate changes in mantle oxygen fugacity. 